Prepared for the U.S. Department of Energy under Contract DE-AC05-76RL01830

\title{
Radiation Detection Scenario Analysis Toolbox (RADSAT) Test Case Implementation Final Report
}

MW Shaver

September 2010

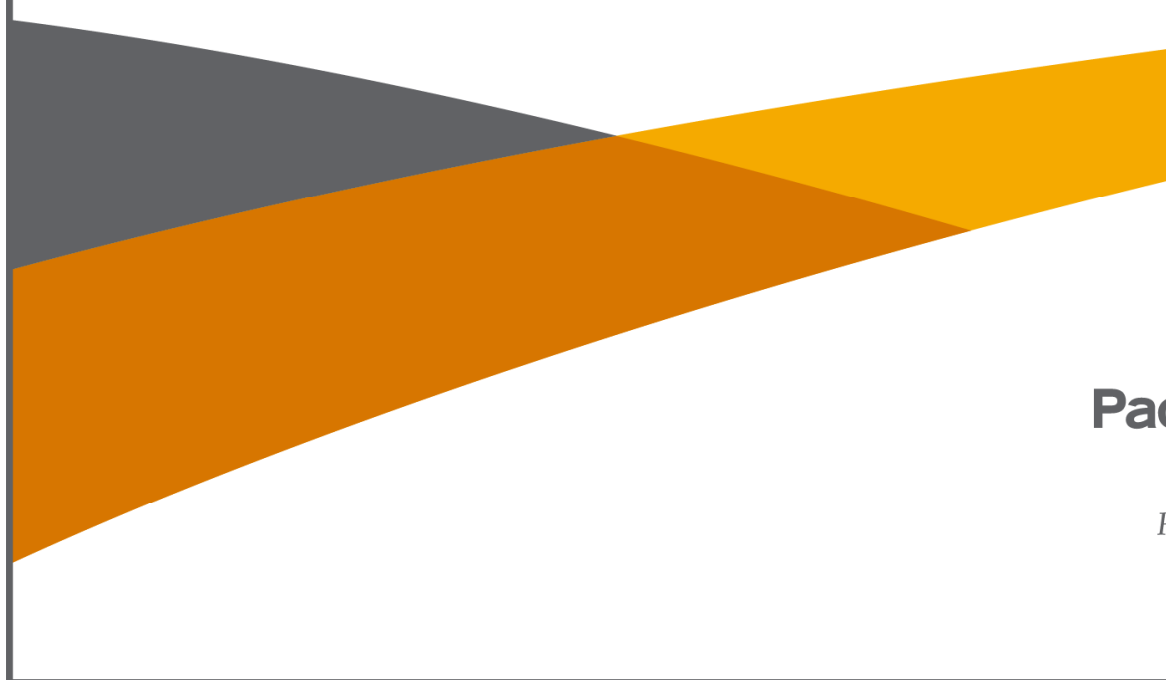




\title{
DISCLAIMER
}

This report was prepared as an account of work sponsored by an agency of the United States Government. Neither the United States Government nor any agency thereof, nor Battelle Memorial Institute, nor any of their employees, makes any warranty, express or implied, or assumes any legal liability or responsibility for the accuracy, completeness, or usefulness of any information, apparatus, product, or process disclosed, or represents that its use would not infringe privately owned rights. Reference herein to any specific commercial product, process, or service by trade name, trademark, manufacturer, or otherwise does not necessarily constitute or imply its endorsement, recommendation, or favoring by the United States Government or any agency thereof, or Battelle Memorial Institute. The views and opinions of authors expressed herein do not necessarily state or reflect those of the United States Government or any agency thereof.

\author{
PACIFIC NORTHWEST NATIONAL LABORATORY \\ operated by \\ BATTELLE \\ for the \\ UNITED STATES DEPARTMENT OF ENERGY \\ under Contract DE-AC05-76RL01830
}

Printed in the United States of America
Available to DOE and DOE contractors from the Office of Scientific and Technical Information,
P.O. Box 62, Oak Ridge, TN 37831-0062;
ph: (865) 576-8401
fax: $(865)$ 576-5728
email: reports@adonis.osti.gov

\begin{abstract}
Available to the public from the National Technical Information Service, U.S. Department of Commerce, 5285 Port Royal Rd., Springfield, VA 22161 ph: (800) 553-6847 fax: $(703) 605-6900$ email: orders@ntis.fedworld.gov online ordering: http://www.ntis.gov/ordering.htm
\end{abstract}

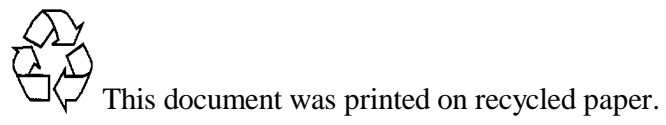




\section{Radiation Detection Scenario Analysis Toolbox (RADSAT) Test Case Implementation Final Report}

MW Shaver

September 2010

Prepared for

the U.S. Department Of Energy

under Contract DE-AC05-76RL01830

Pacific Northwest National Laboratory

Richland, WA 99354 


\section{Summary}

This project was designed to demonstrate the use of the Radiation Detection Scenario Analysis Toolbox (RADSAT) radiation detection transport modeling package (developed in a previous NA-22 project) for specific radiation detection scenarios important to proliferation detection. RADSAT is founded on a 3-dimensional deterministic radiation transport solver capable of efficiently computing the radiation field at all points in complex, large-scale problems (e.g. buildings). These results are then coupled to a Monte Carlo detector response simulator. For this project Pacific Northwest National Laboratory (PNNL) staff applied RADSAT to two specific instruments and scenarios, in close collaboration with the developers of each technology. The first is a neutron-scatter camera for detection of concealed neutron-emitting sources developed at Sandia National Laboratories (SNL) and the second is a spent-fuel verification system for fuel assemblies in storage casks developed at Idaho National Laboratory (INL).

To simulate detector responses, RADSAT uses a source modified version of Monte Carlo NParticle Version 5 (MCNP5), which does not produce all of the information required to produce images for the scatter camera system. SNL models the scatter camera with Monte Carlo NParticle - Politecnico di Milano (MCNP-PoliMi), which utilizes more accurate neutron elastic scattering physics and secondary gamma-ray production essential for modeling time-dependent events in multiple detectors. Therefore, RADSAT currently will not work for generating images for the scatter camera.

However, it was demonstrated that RADSAT calculated the correct individual detector response, which indicates that RADSAT could be an appropriate tool for modeling neutron scatter cameras if MCNP-PoliMi were to be used as the RADSAT Monte Carlo detector response module. Incorporating MCNP-PoliMi into RADSAT in addition to MCNP5 would require a minimal amount of code development, testing, and quality assurance. In terms of computational run time, for very simple low scattering scenarios, RADSAT may not have a computational speed advantage over MCNP5, but for more complicated, larger, or highly scattering problems (which are probably more realistic), RADSAT may have computational run times shorter than MCNP5.

For the simulation of the spent fuel cask gamma-ray scanner, the solution accuracies for the RADSAT simulations were reasonable (less than $15 \%$ different from experimental results) and comparable to the current standard (MCNPX) for all of the compared values for both full and empty assembly positions. RADSAT also ran 60\% faster than Monte Carlo N-Particle eXtended (MCNPX), with both codes optimized for speed. In addition, the time to set up a RADSAT run is probably much less than the time to set up and optimize an MCNPX input deck with appropriate variance reduction, making the total time to solution even faster for RADSAT than just the computational run time advantage. 


\section{Contents}

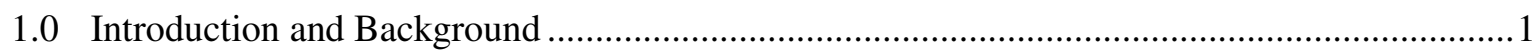

1.1 RADSAT for SNM Movement Detection Scenarios …..................................................... 1

2.0 Modeling of the Fast Neutron Scatter Camera from SNL ....................................................... 3

2.1 Modeling of the First (Bare, Unshielded) ${ }^{252} \mathrm{Cf}$ Source Test Case for the Neutron

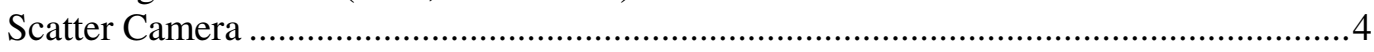

2.2 Modeling of the Second (Polyethylene Pig Shielded) ${ }^{252}$ Cf Source Test Case for the

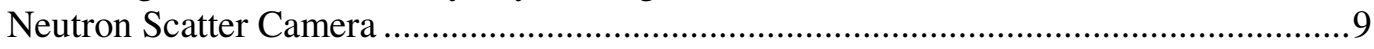

3.0 Modeling of the Spent Fuel Cask Gamma-Ray Scanner from INL ...................................... 15

3.1 Modeling of the Full C2 Assembly Position ................................................................ 19

3.2 Modeling of the Empty A4 Assembly Position..............................................................20

3.3 Comparison of the Modeling of the Full C2 and Empty A4 Assembly Positions............21

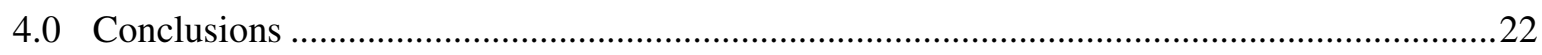

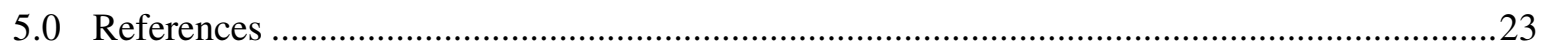




\section{Figures}

Figure 1. The first step in the processing of the MCNP-PoliMi output with the ROOT code [9].....3

Figure 2. MCNP5 Visualization of the first (unshielded) Scatter Camera scenario........................ 4

Figure 3. Comparison of detector responses for the first (unshielded) Scatter Camera scenario. .....5

Figure 4. Comparison of detector intrinsic efficiency for the first (unshielded) Scatter Camera

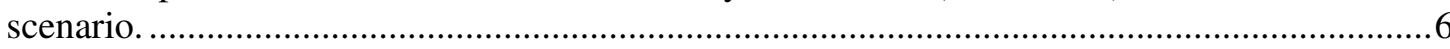

Figure 5. Comparison of detector effective area for the first (unshielded) Scatter Camera scenario.

Figure 6. Experimental and MCNP-PoliMi images for the first (unshielded) Scatter Camera scenario.

Figure 7. Comparison of detector responses for the first (unshielded) Scatter Camera scenario. ..... 8

Figure 8. MCNP5 Visualization of the second (shielded) Scatter Camera scenario....................... 9

Figure 9. Comparison of detector responses for the second (shielded) Scatter Camera scenario.... 10

Figure 10. Comparison of detector intrinsic efficiency for the second (shielded) Scatter Camera scenario.

Figure 11. Comparison of detector effective area for the second (shielded) Scatter Camera scenario.

Figure 12. Experimental and MCNP-PoliMi iages for the second (shielded) Scatter Camera scenario.

Figure 13. Comparison of detector responses for the second (shielded) Scatter Camera scenario. 13

Figure 14. Visualization of the Cask Scanner on a Westinghouse MC-10 Spent Fuel Cask [13]...16

Figure 15. Assembly Scanning Pattern of a Westinghouse MC-10 Spent Fuel Cask [13]............16

Figure 16. Configuration and assembly loading of the Turkey Point spent fuel cask [13]............17

Figure 17. Solid Works CAD model of the spent fuel in the cask used for the Attila geometry .....18

Figure 18. Visualization of the MCNPX Model of the collimated gamma detector.......................18

Figure 19. Comparison of Cask Scanner Detector Response in the full C2 slot............................19

Figure 20. Comparison of Cask Scanner Detector Response in the empty A4 slot......................20

Figure 21. Comparison of Cask Scanner Detector Response in the full C2 and empty A4 slots.....21

\section{Tables}

Table 1. Comparison of Results for the first (unshielded) Scatter Camera scenario........................8

Table 2. Comparison of Results for the second (shielded) Scatter Camera scenario ...................... 13

Table 3. Comparison of Results for the Cask Scanner in the full C2 slot .....................................19

Table 4. Comparison of Results for the Cask Scanner in the empty A4 slot ..................................20 


\subsection{Introduction and Background}

The primary objective of this one-year effort was to exercise the Radiation Detection Scenario Analysis Toolbox (RADSAT) package in modeling problems relevant to proliferation detection, and to evaluate RADSAT's efficacy as an assessment and design optimization tool for technologies being developed in the Special Nuclear Material (SNM) Movement Detection portfolio. The primary metrics for evaluation (and comparison to purely Monte Carlo methods) were solution accuracy and computational efficiency. The two case-study instrument development projects were the Neutron Scatter Camera at Sandia National Laboratories (SNL) and the Spent Fuel Cask Gamma-Ray Scanner at Idaho National Laboratory (INL).

\subsection{RADSAT for SNM Movement Detection Scenarios}

Radiation transport methods fall into one of two broad categories: stochastic (Monte Carlo) and deterministic. Monte Carlo methods are typically the tool of choice for simulating the response of neutron and gamma-ray detectors operating in national security settings, but deterministic codes that discretize the linear Boltzmann transport equation in space, angle, and energy offer potential advantages in computational efficiency for many complex 3-D scenarios, particularly those with a high degree of attenuation or scattering. The RADSAT package was developed to couple both methods to realize the benefits and mitigate the shortcomings of both methods. To do so, RADSAT is founded on a 3dimensional deterministic radiation transport solver capable of efficiently computing the radiation field at all points in complex, large-scale problems. The deterministically calculated fluxes at locations of interest are then converted into Monte Carlo source terms. These source terms are then used in Monte Carlo simulations of radiation transport through radiation detectors to determine the detector response. Currently, the deterministic code that RADSAT uses is Attila [1] and the Monte Carlo code it is coupled to is source modified version Monte Carlo N-Particle Version 5 (MCNP5) [2] with the coupling algorithm.

RADSAT was developed by PNNL during FY06-FY09 under support from the NA-22 Simulation, Analysis, and Modeling portfolio. Through a series of benchmarking problems, RADSAT was shown to provide considerable advantages (in terms of computational time) over Monte Carlo methods for a number of scenario types, particularly those with a high degree of scatter or attenuation. These computational-time benefits, however, do not necessarily extend to all problem types due to issues associated with deterministic transport methods (e.g. mitigation of ray effects, mesh refinement, solutionaccuracy assessment). Applications considered in previous RADSAT development included radiation portal monitors, instrumented containers for in-transit monitoring of maritime cargo, $\mathrm{UF}_{6}$ cylinder verification for fuel-cycle safeguards, and prompt gamma neutron activation analysis for chemical munitions assay [3][4][5][6].

Feasibility studies for particular radiation detection scenarios, requested by DOE and other agencies, are a common exercise at DOE laboratories and were the primary motivating application for RADSAT development. Potential users include SNM Movement Detection Research and Development (R\&D) projects that have plans to utilize modeling for viability studies, design optimization or performance evaluation. Other potential users of RADSAT would include emergency response teams, analysts at the United States Department of Energy (DOE) laboratories, and intelligence agencies. Modeling tools such as RADSAT are also frequently used by instrument developers for design optimization. This demonstration project will provide a valuable assessment of how well RADSAT performs when used for these purposes in instrument development projects relevant to proliferation detection. The two case-study instrument development projects will be the Neutron Scatter Camera at Sandia National Laboratories (SNL) and the Spent Fuel Cask Scanner at Idaho National Laboratory (INL). 



\subsection{Modeling of the Fast Neutron Scatter Camera from SNL}

For the simulations of the Neutron Scatter Camera, Sandia National Laboratories (SNL) uses Monte Carlo N-Particle - Politecnico di Milano (MCNP-PoliMi) because it has been designed to model interactions as closely as possible by faithfully reproducing the physics for a Monte Carlo scattering event [7][8]. MCNP-PoliMi is a modified version of MCNP4c. The concern with MCNP5 is that in its source coding, it neglects energy/ momentum conservation in its variance reduction in order to reduce the computation time needed to estimate average quantities (be that energy deposition, track length, and other tally variables). This is very problematic when tracking single particles between multiple detectors is necessary, as it is in the scatter camera. While the average scattering quantities should be correct, individual particles need to be tracked correctly for coincidence counting.

For a simulation, events are generated from simulated sources in MCNP-PoliMi to determine the total neutron energy deposition per interaction within the detectors. It can happen that a neutron interacts by scattering multiple times in multiple detectors. The ROOT framework is then used to process the calculated collection of energy depositions to derive detector hits. A real detector's response is simulated with experimental inputs from calibration files; these are the energy, pulse shape discrimination, and time-of-flight. These calibrations can be used to model things like resolution, gain, offset, etc. A flow diagram of the first step in the ROOT code is shown below in Figure 1.

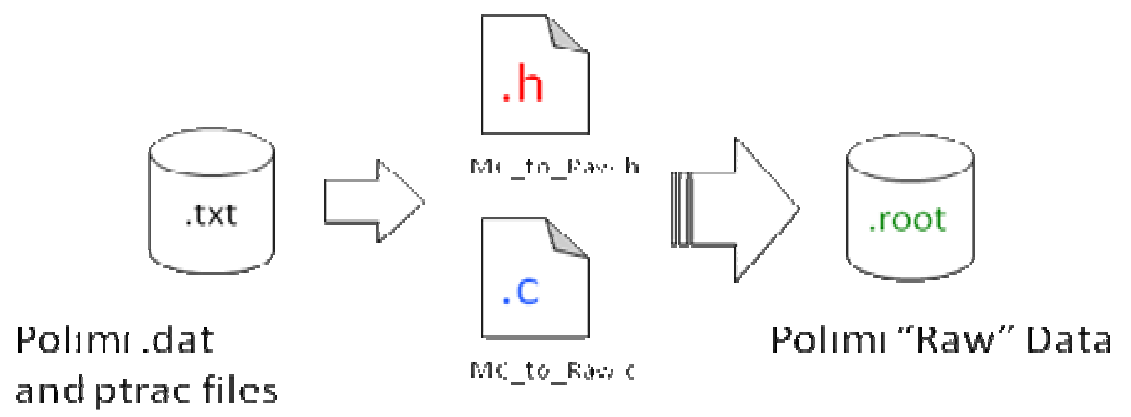

Figure 1. The first step in the processing of the MCNP-PoliMi output with the ROOT code [9].

At this point, the MCNP-PoliMi data resembles real, experimental data, and its analysis follows the same analysis chain as the real data. The data is then processed and imaged. The nominal set of cuts is to ensure that the energies and the pulse shape discriminator (PSD) are not negative or saturated. To image, it is required that a neutron scatters in both a front and rear plane detector, and that the time-of-flight (TOF) is reasonable. The PSD is used to give the likelihood for being a neutron or a gamma, and the TOF also enters into this likelihood analysis. The cuts are hard coded into the analysis [10][11].

The detector transport module of RADSAT, called the detector response function (DRF), currently uses MCNP5, so it does not produce all of the information required for the SNL scatter camera data processing code, as described above. Thus, RADSAT currently will not work for generating images for the scatter camera system. However, with minimal code development, MCNP-PoliMi could be added as an alternate detector response module in RADSAT and the simulations would be possible.

Until then, another metric we can use to compare simulated results from RADSAT and MCNP-PoliMi is the detector response (F8) tally. Demonstrating that the count rates and spectra in the detectors are similar for RADSAT, MCNP5, and MCNP-PoliMi with the F8 tally may indicate that RADSAT would be an appropriate tool for modeling scatter cameras if MCNP-PoliMi were used as the RADSAT DRF. This is because it would prove that the particle transport is handled correctly throughout the problem, 
excepting for the particle by particle Monte Carlo scattering information between detectors needed for the image processing. However, if the average quantities in the two codes match, then the modifications made by MCNP-PoliMi would be the only difference. Therefore, the main comparison metric between all of the codes is the sum of the normalized detector responses in all of the detectors.

To test this analysis, the simulations of two test cases done at SNL were compared to the experimental data. The first test case for comparison is an unshielded, $104 \mu \mathrm{Ci},{ }^{252} \mathrm{Cf}$ source located three meters away from the front of the detector. This test had a count time of just less than 10 minutes. The second case for comparison was the same $104 \mu \mathrm{Ci},{ }^{252} \mathrm{Cf}$ source, but shielded with a cylindrical polyethylene pig and located two meters out, sixty $\mathrm{cm}$ left, and one meter down from the front of the detector. This test had a count time of just less than 31/2 hours. For both cases, MCNP-PoliMi, MCNP5, and RADSAT are all used to compare to the experimental data. The MCNP model of the detector was provided by SNL and used for the MCNP-PoliMi, MCNP5, and the detector response module in the RADSAT simulation. This provided a consistent and correct detector model for all simulations which allows for a consistent comparison of the codes.

To compare the run times, all actual computer run times were normalized to a single Intel Xeon E5506 $\mathrm{CPU}$ at $2.13 \mathrm{GHz}$ on a machine with a Microsoft Windows operating system. While most of the runs were actually run on a machine that matches those specifications, some were run on a slightly different machine, so they are normalized by processor speed to provide an appropriate and consistent comparison. No variance reduction was used in any of the MCNP5 cases or the detector response module in RADSAT so that the run times compare RADSAT to purely analog Monte Carlo transport.

\subsection{Modeling of the First (Bare, Unshielded) ${ }^{252} \mathrm{Cf}$ Source Test Case for the Neutron Scatter Camera}

The first scenario is the simplest test case, being a bare source and no shielding between the source and the detector. Simulations of this scenario are very computationally inexpensive because there is no scattering except for in the detector. A visualization of the MCNP5 model of the scenario is shown below in Figure 2.

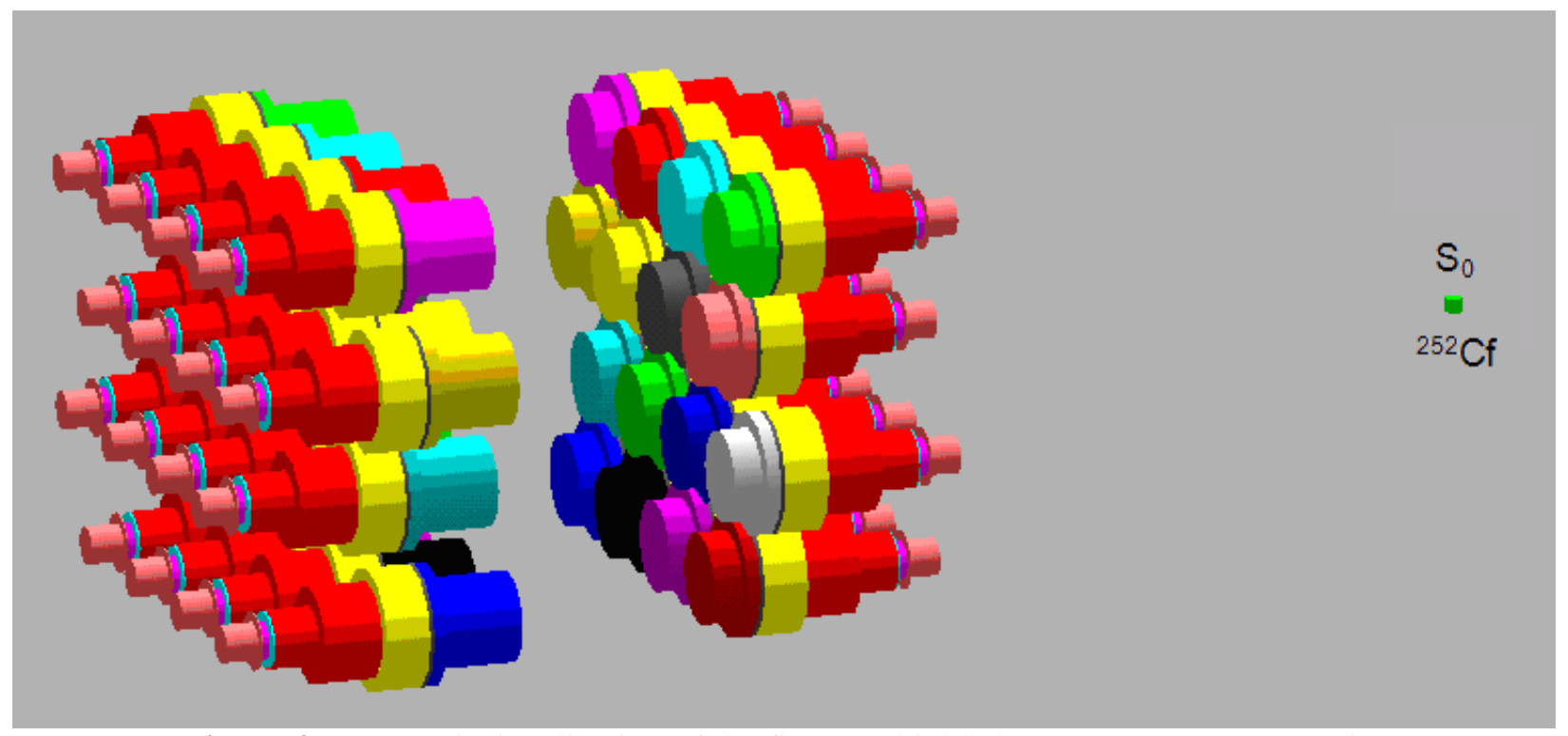

Figure 2. MCNP5 Visualization of the first (unshielded) Scatter Camera scenario. 
For the RADSAT simulation of the bare ${ }^{252} \mathrm{Cf}$ scenario the mesh is a void block $50 \mathrm{~cm} \times 50 \mathrm{~cm} \mathrm{x} 330 \mathrm{~cm}$ meshed to a tightness of $0.1 \mathrm{~m}$. The cross section library used was kynea_4Ee18. The maximum outer and inner iterations were both 100, and the convergence criterion was 1E-4. The quadrature used was Triangle Chebychev Double Legendre, $S_{N}=12, P_{N}=3$, with Galerkin Scattering turned on. While this is much more scattering fidelity than needed for the transport, it is necessary to have all of the angular data when porting to the detector response module in RADSAT. An uncollided point source flux edit was taken by space and energy at points centered on the front face of each detector in the front array. There were no collided calculations performed as there is no material in the far field transport for the source to scatter on. The calculation was simply a ray-tracing calculation and the FSDS calculation halted after this. However, an uncollided flux file was created, so the uncollided scalar flux edits at the detectors were merged with a blank collided file (all values were 0 ) in order to use the merger application to generate an LCF file that was compatible with the MCNP5 source subroutine executable.

A plot comparing the sum of the detector responses are shown below in Figure 3. As can be seen, all of the simulation tools yield consistent results both with each other and with the experimental data.

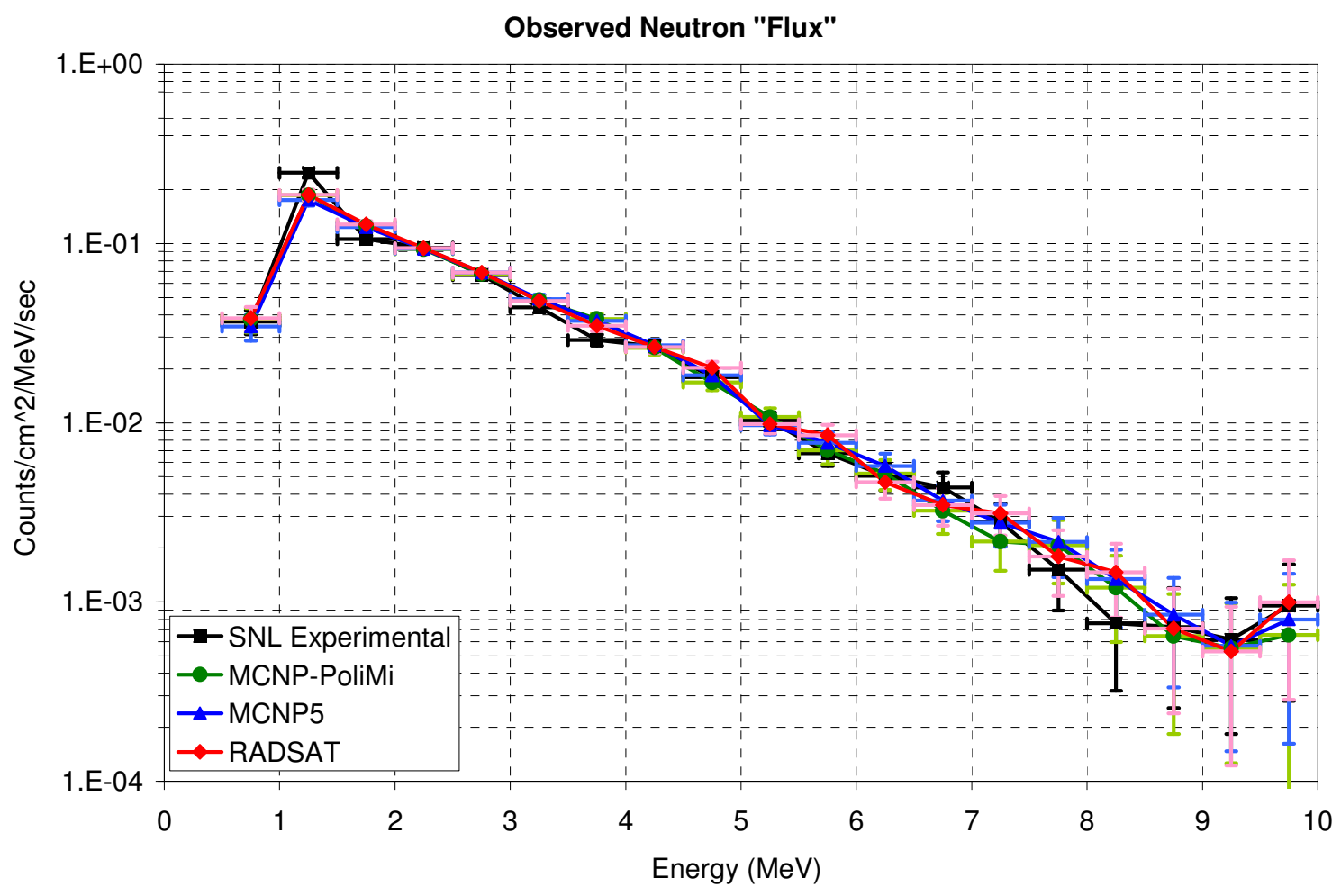

Figure 3. Comparison of detector responses for the first (unshielded) Scatter Camera scenario.

While post-processing these data from the experiment and the MCNP-PoliMi run, SNL's ROOT code calculates the intrinsic efficiency of the detectors. This is a ratio of how many particles enter the detector to how many contribute a coincidence count that is used for the image. A plot of the energy dependent intrinsic efficiency of the detector is shown below in Figure 4. From this parameter, a "neutron effective area" is also calculated in the ROOT code. This parameter is the surface area of the detector multiplied by the intrinsic efficiency of the detector. Essentially, this represents the cross section of the detector that the neutrons from the source are exposed to. An energy dependent plot of this parameter is shown below in Figure 5. As can be seen, the MCNP-PoliMi results are consistent with the experimental results. 


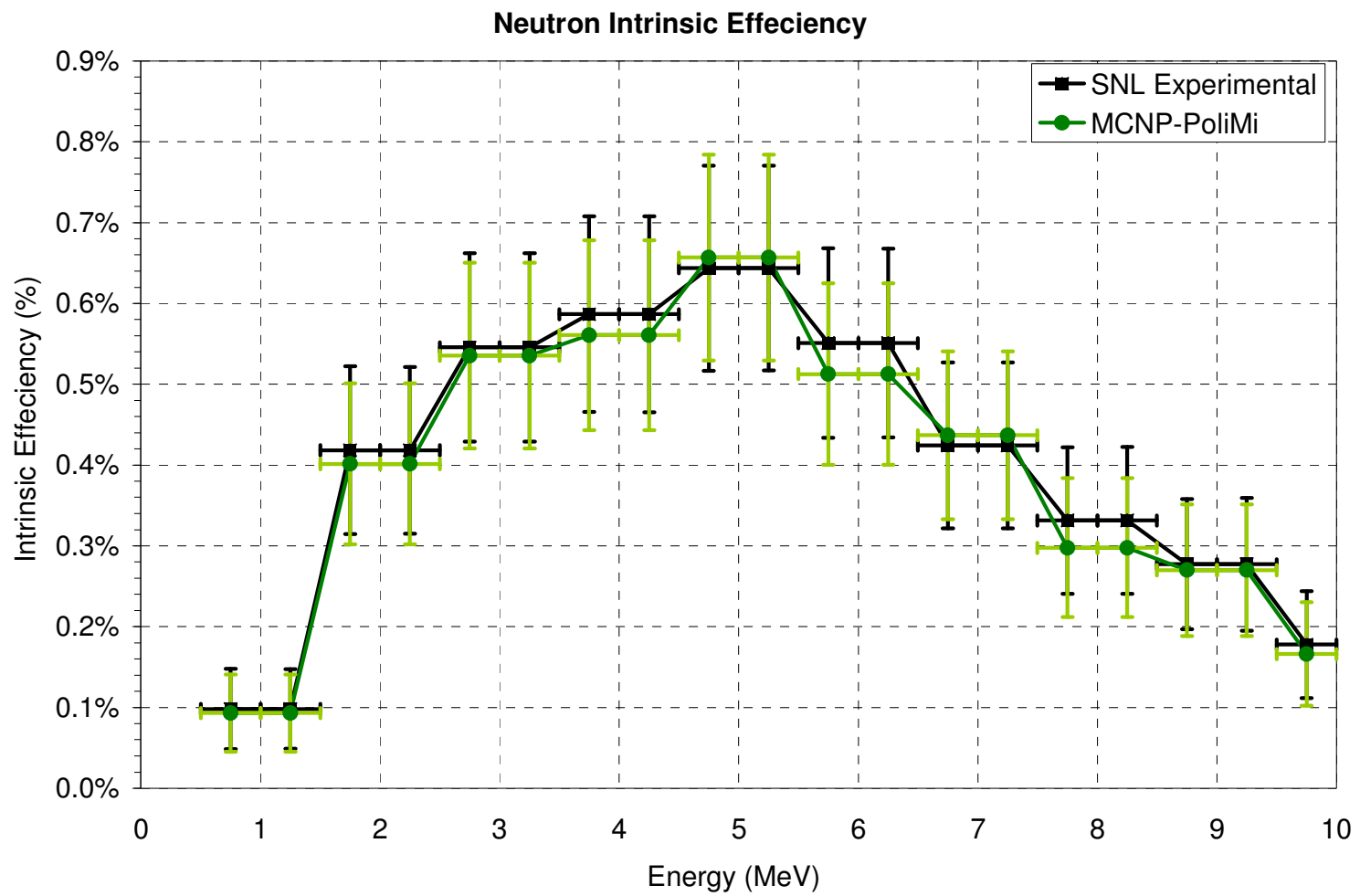

Figure 4. Comparison of detector intrinsic efficiency for the first (unshielded) Scatter Camera scenario.

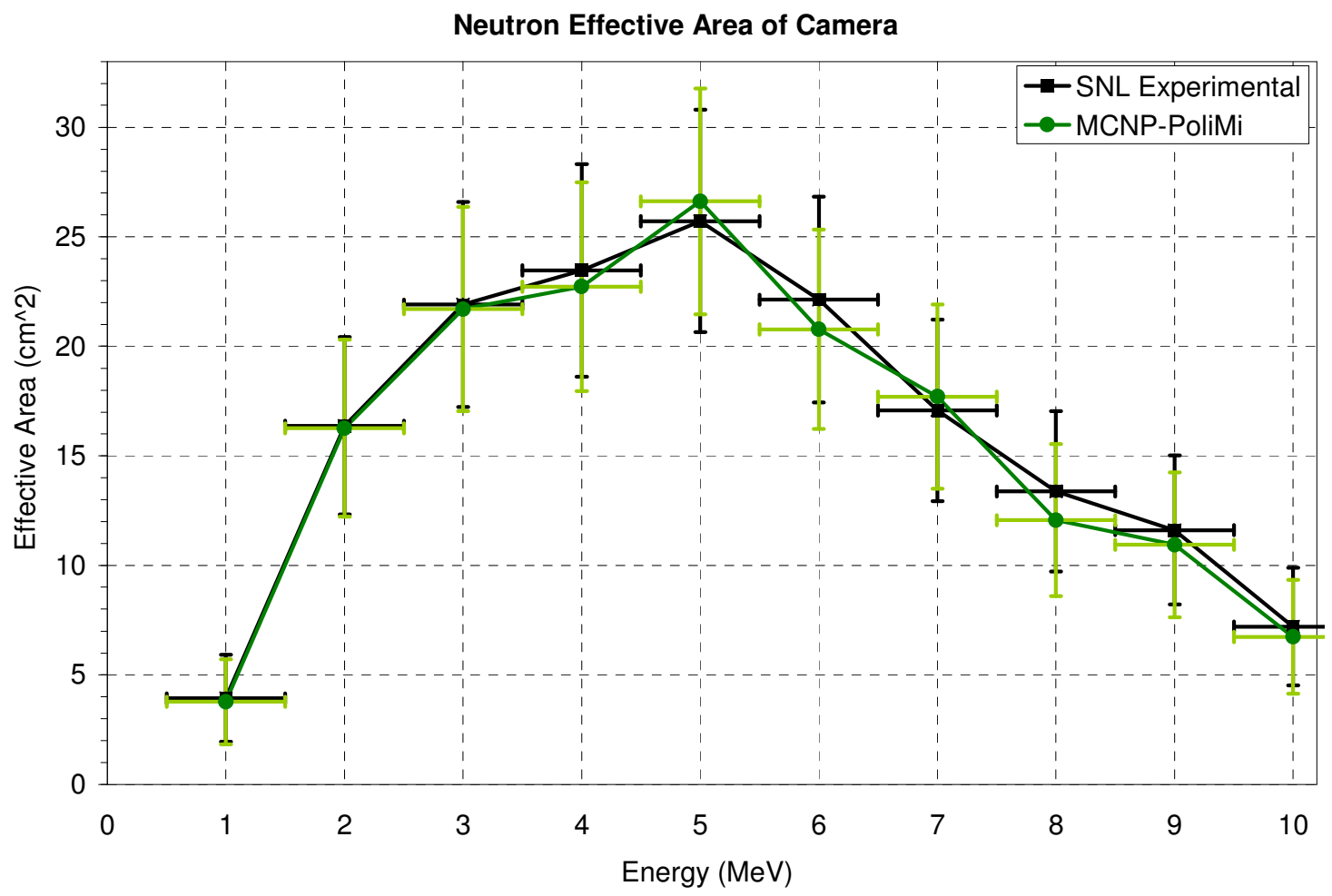

Figure 5. Comparison of detector effective area for the first (unshielded) Scatter Camera scenario. 
When comparing the actual coincidence counting detector response that leads to a count for the image, there two methods of comparing solution accuracy. The first is the image that it produces and the second is the energy spectra of the counts. Because of the limitations in MCNP5 previously mentioned, only the experimental data and the MCNP-PoliMi run can actually generate an image. These are both shown below respectively in Figure 6. The black dots represent the actual location of the source. For both the experiment and MCNP-PoliMi, the correct location of the source is encompassed by the maximum likelihood region indicated in the images.
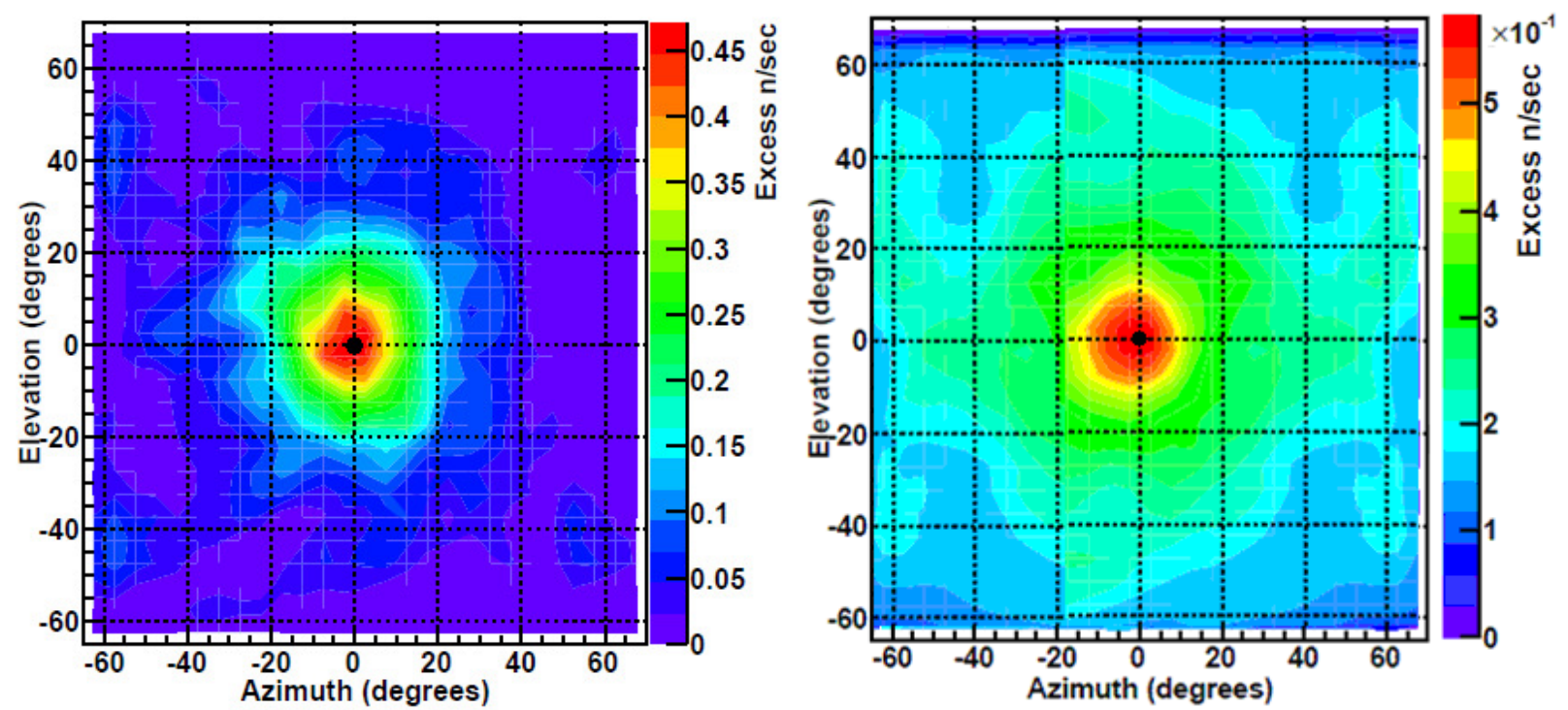

Figure 6. Experimental and MCNP-PoliMi images for the first (unshielded) Scatter Camera scenario.

The energy spectra of the counts that generated the images above in Figure 6 are also important to compare. For the MCNP5 and RADSAT simulations, the MCNP-PoliMi intrinsic efficiency is assumed to generate the spectra. This is what the spectra would look for those two codes if the same modification in the MCNP-PoliMi scattering were made in MCNP5 and RADSAT. A plot of these comparisons are shown below in Figure 7. As can be seen, they once again yield consistent results. 


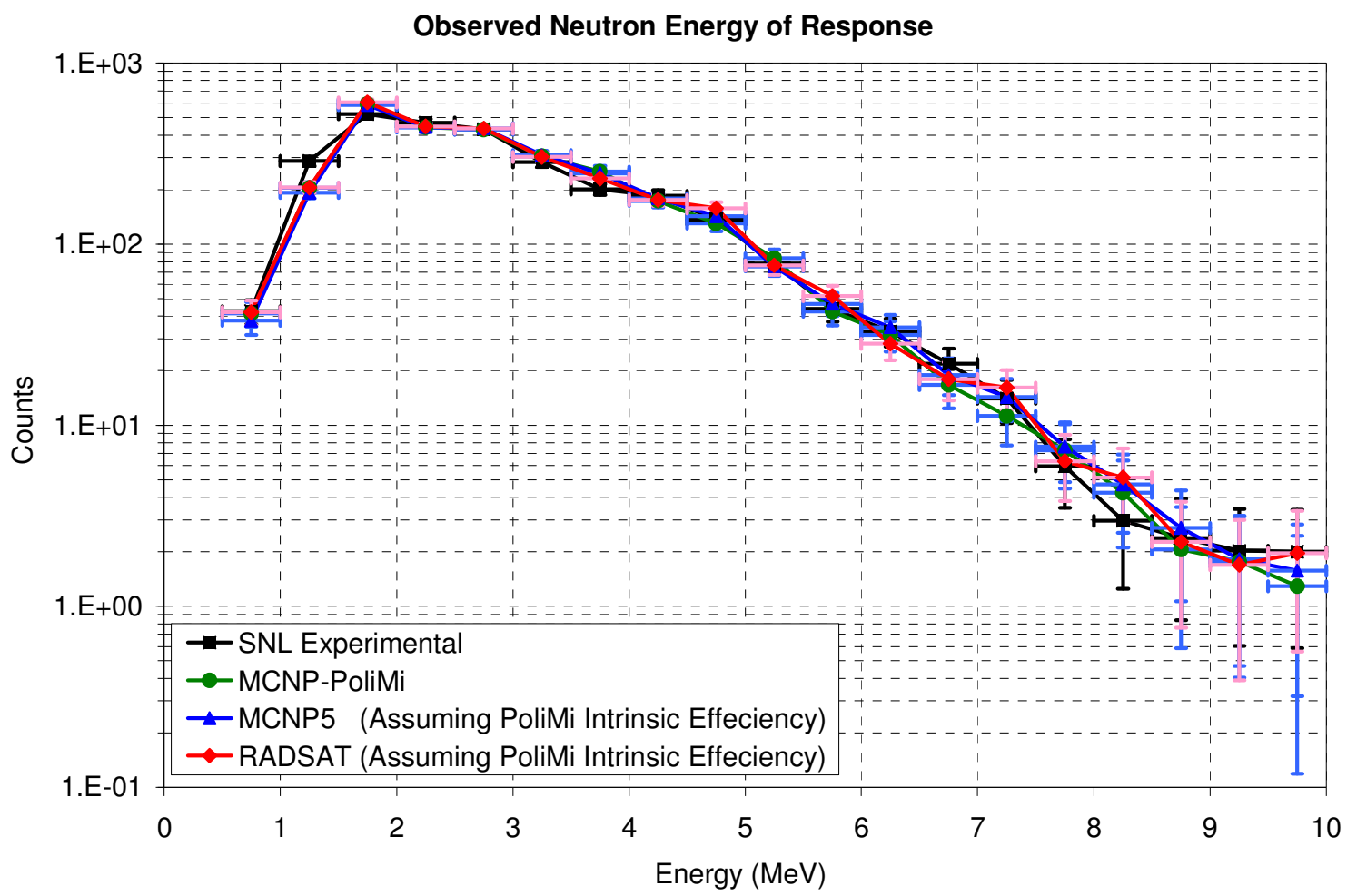

Figure 7. Comparison of detector responses for the first (unshielded) Scatter Camera scenario.

Along with solution accuracy (both image and spectra), the other performance metric is computational run time. The results of both the computational accuracy and run times are compared below in Table 1 . First, the MCNP-PoliMi results matches the experimental data for both the image and the spectra. This shows that MCNP-PoliMi can faithfully simulate this scenario. MCNP5 and RADSAT results also match the experimental data (as well as MCNP-PoliMi) for the bulk transport and individual detector response. Assuming they would have the same intrinsic efficiency as MCNP- PoliMi, their spectra of the coincidence counts would match as well.

As for the run time, both MCNP5 and MCNP-PoliMi took about 44 minutes to simulate the almost 10 minute experimental run, while the RADSAT simulation took only about 16 minutes to simulate the same amount of real time. This shows that there is possibly a computational advantage to using RADSAT for very simple cases with no scattering because Attila only has to run a ray tracing calculation. However, it could be possible to reduce the MCNP5 run times dramatically using variance reduction such as source biasing. For cases this simple, with no scattering, MCNP5, with variance reduction, could run faster than RADSAT. However, most real life scenarios will have scattering in them which would increase the run time of both methods.

Table 1. Comparison of Results for the first (unshielded) Scatter Camera scenario

\begin{tabular}{|c|c|c|c|}
\hline & $\begin{array}{c}\text { Image Location Solution } \\
\text { Accuracy (degrees) }\end{array}$ & $\begin{array}{c}\text { Spectral Solution } \\
\text { Accuracy }(\%)\end{array}$ & $\begin{array}{c}\text { Run Times for } \\
\text { Bare Source (min) }\end{array}$ \\
\hline Experiment & $\sim 0.5^{\mathbf{0}} \pm \sim 15^{\circ}$ & - & 9.73 \\
\hline MCNP-PoliMi & $\sim 1.5^{\mathbf{o}} \pm \sim 15^{\circ}$ & $11.4 \%$ & 43.79 \\
\hline MCNP5 & - & $11.3 \%$ & 43.71 \\
\hline RADSAT & - & $11.5 \%$ & 15.95 \\
\hline
\end{tabular}




\subsection{Modeling of the Second (Polyethylene Pig Shielded) ${ }^{252} \mathrm{Cf}$ Source Test Case for the Neutron Scatter Camera}

To test a somewhat more representative scenario of how the Neutron Scatter Camera would be used, the same ${ }^{252} \mathrm{Cf}$ source as the first scenario was placed in a Polyethylene pig shield to provide both shielding and moderation of the neutron source. The source was also placed off center to provide a more complicated image reconstruction. A diagram of this scenario is shown below in Figure 8.

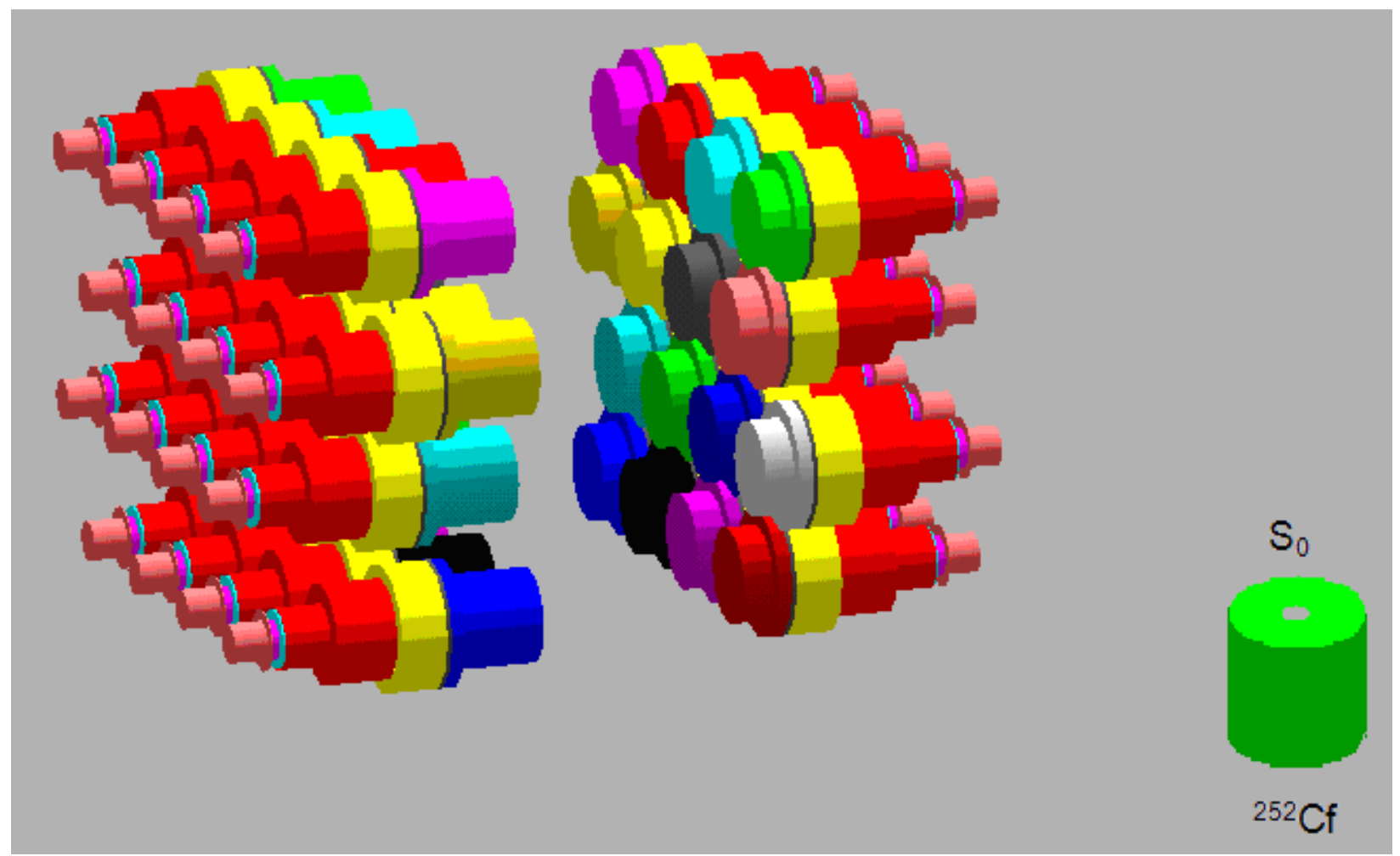

Figure 8. MCNP5 Visualization of the second (shielded) Scatter Camera scenario.

For the RADSAT simulation a first scattered distributed source (FSDS) calculation was performed angular flux distribution within the polyethylene that was stored as a .dat file. An Attila calculation was performed, using this .dat file as a volume source to generate an angular flux distribution on the surface of the polyethylene cylinder. The sn2ptsrc utility was used to collapse this angular flux distribution into a non-isotropic point source. This point source was used for another FSDS calculation that calculated the point edit angular flux in front of the center of each individual detector in the front array of the scatter camera. This second Attila run was comparable to the run in the first scenario. The results were then used as input in an MCNP5 calculation using a source subroutine.

The mesh is composed of two regions. The first is a large cylinder with a small cylinder bored out of the center of the top half of the large cylinder. The large cylinder has a diameter of $26.67 \mathrm{~cm}$ and a height of $30.48 \mathrm{~cm}$. The small cylinder has a diameter of $6.35 \mathrm{~cm}$ and a height of $15.24 \mathrm{~cm}$. A void box is placed around the large cylinder. The box is $36 \mathrm{~cm} \times 36 \mathrm{~cm} \times 36 \mathrm{~cm}$. The large cylinder is filled with polyethylene with a density of $1 \mathrm{~g} / \mathrm{cc}$ and everything else is void. The region filled with polyethylene is meshed to a tightness of $0.05 \mathrm{~m}$, while the void is meshed to a tightness of $1 \mathrm{~m}$. The cross section library used was kynea_4Ee18. The quadrature used was Square Chebychev Lobatto, with $\mathrm{S}_{\mathrm{N}}=32, \mathrm{P}_{\mathrm{N}}=3$, and Galerkin Scattering turned on. The maximum outer iterations were 50 and the maximum inner iterations were 100. The convergence criterion was 1E-4. An uncollided point source flux edit was taken by space 
and energy at points centered on the front face of each detector in the front array. Those uncollided scalar flux edits were then merged with a blank collided file (all values were 0 ) in order to used the merger application to generate an LCF file that was compatible with the MCNP5 source subroutine executable.

A plot comparing the sum of the detector responses are shown below in Figure 9. As can be seen, all of the simulation tools yield consistent results both with each other and with the experimental data.

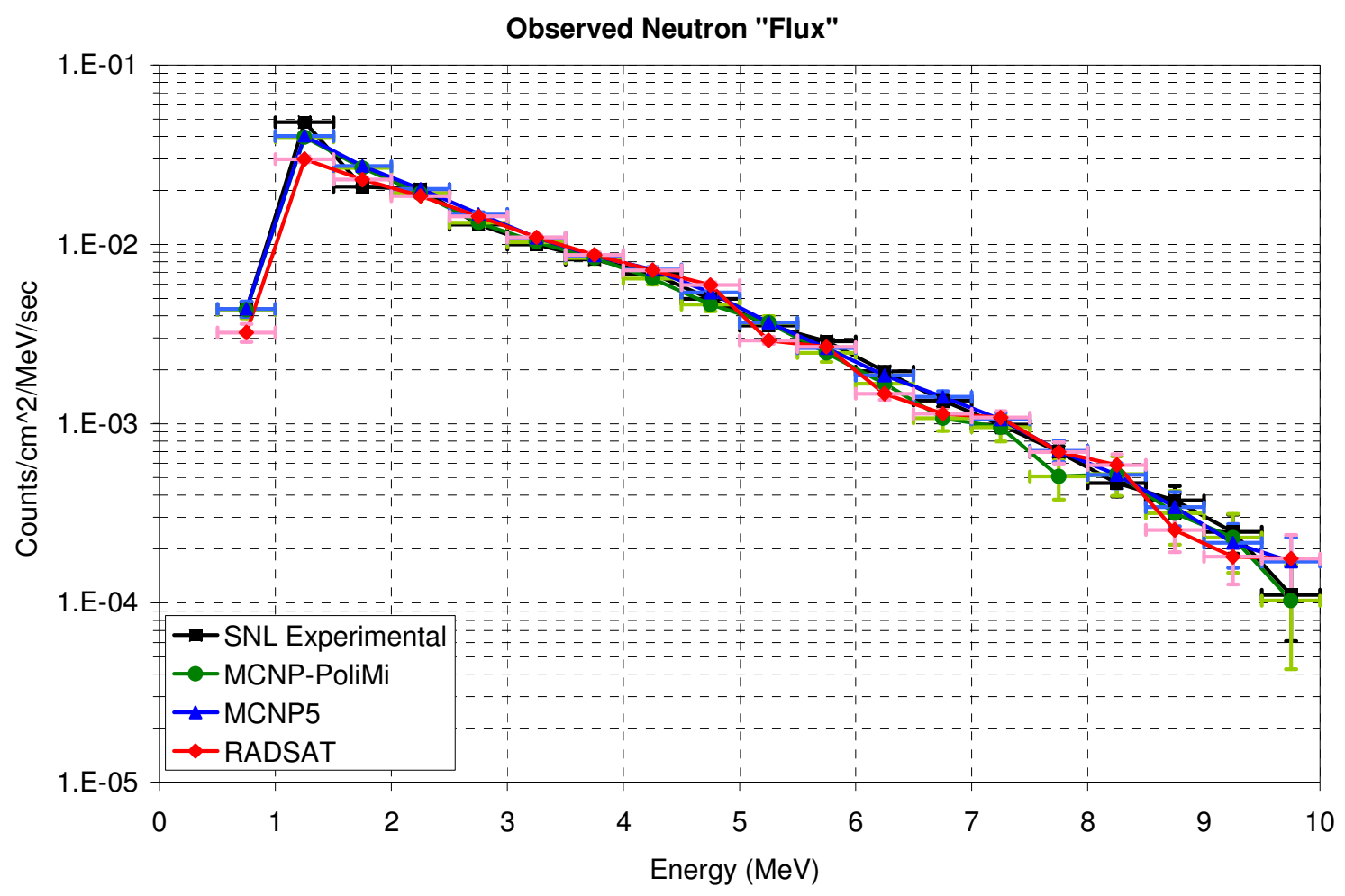

Figure 9. Comparison of detector responses for the second (shielded) Scatter Camera scenario.

While post-processing these data from the experiment and the MCNP-PoliMi run, SNL's ROOT code calculates the intrinsic efficiency of the detectors. This is a ratio of how many particles enter the detector to how many contribute a coincidence count that is used for the image. A plot of the energy dependent intrinsic efficiency of the detector is shown below in Figure 10. From this parameter, a "neutron effective area" is also calculated in the ROOT code. This parameter is the surface area of the detector multiplied by the intrinsic efficiency of the detector. Essentially, this represents the cross section of the detector that the neutrons from the source are exposed to. An energy dependent plot of this parameter is shown below in Figure 11. As can be seen, the MCNP-PoliMi results are consistent with the experimental results. 


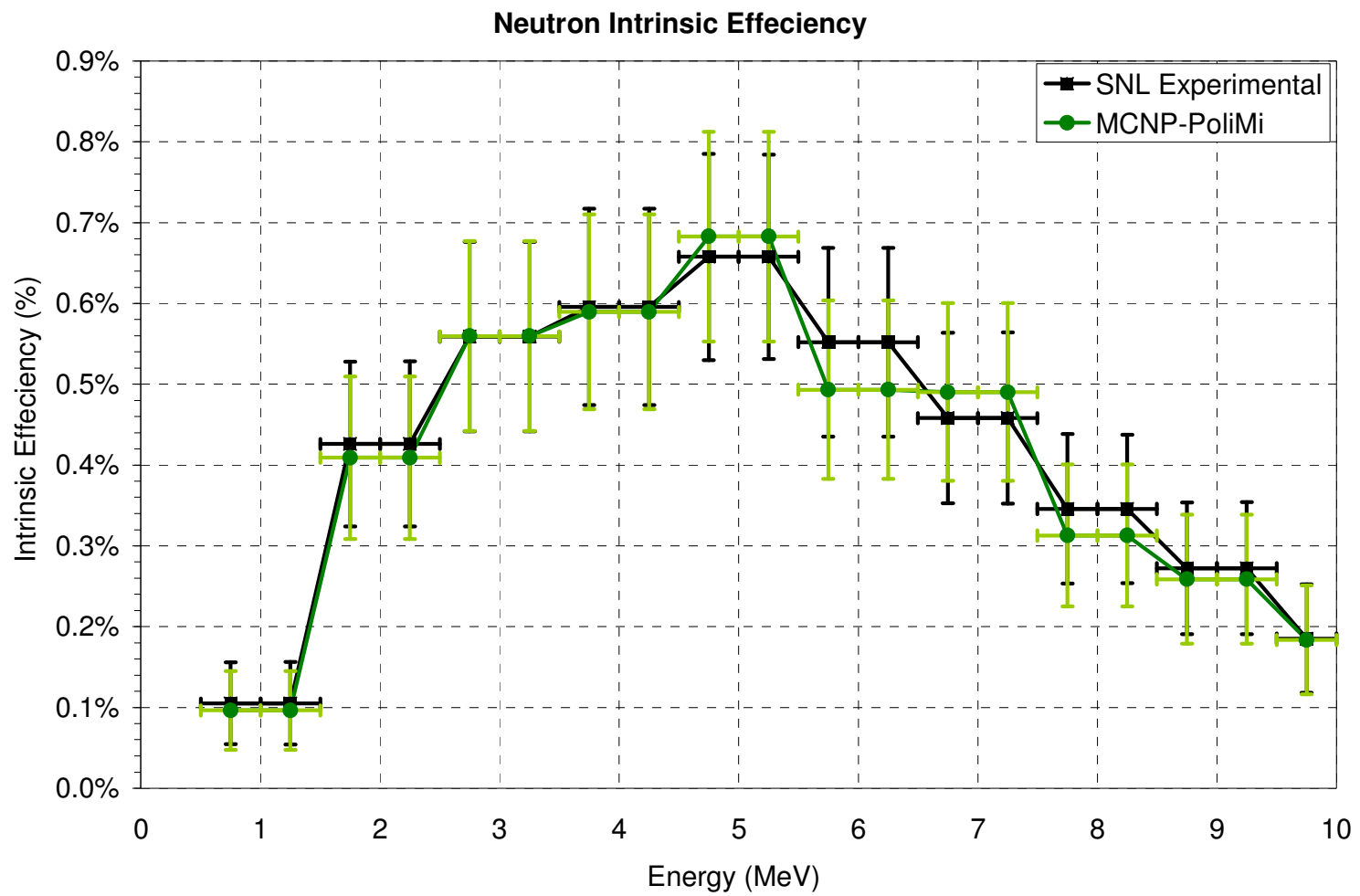

Figure 10. Comparison of detector intrinsic efficiency for the second (shielded) Scatter Camera scenario.

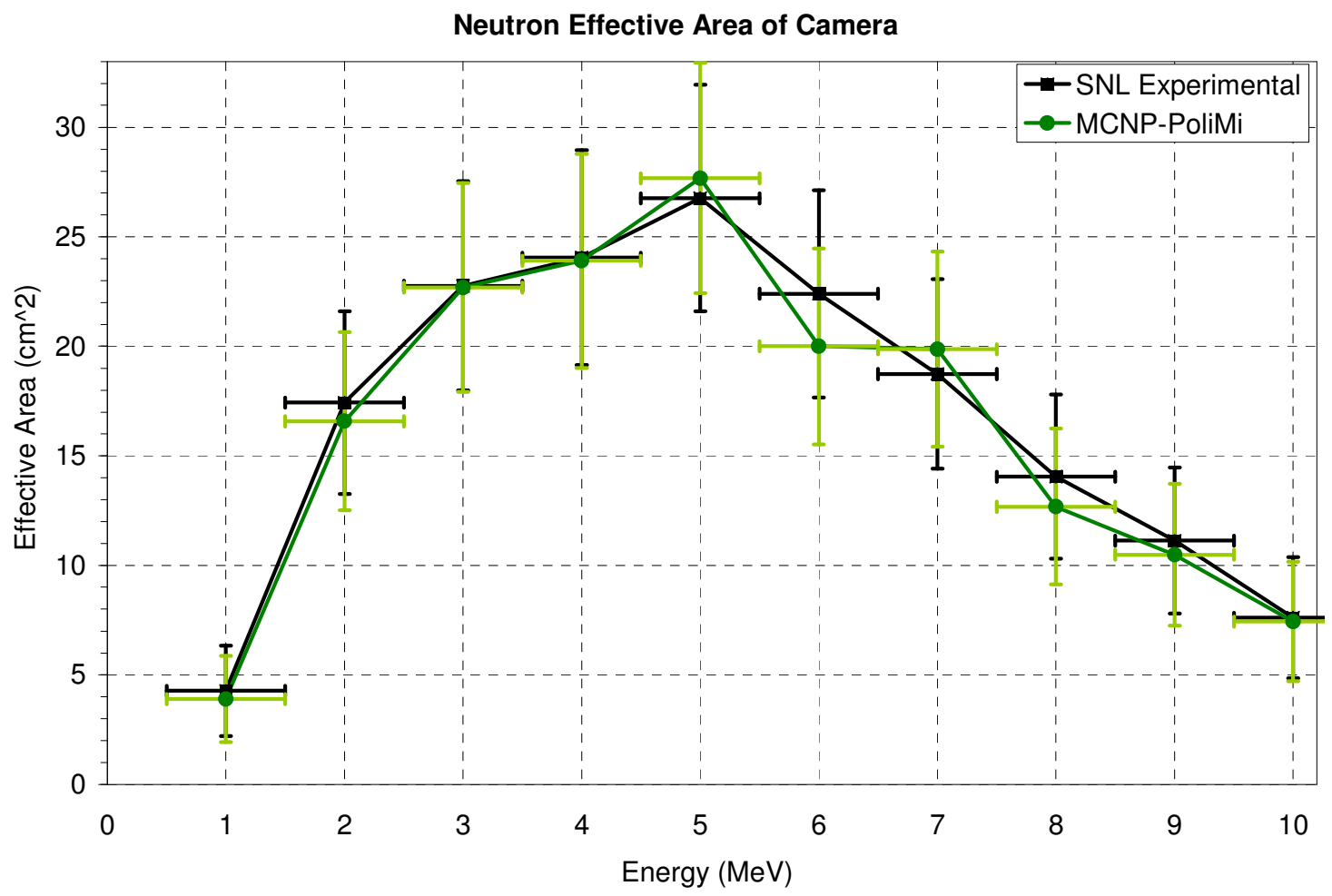

Figure 11. Comparison of detector effective area for the second (shielded) Scatter Camera scenario. 
When comparing the actual coincidence counting detector response that leads to a count for the image, there two methods of comparing solution accuracy. The first is the image that it produces and the second is the energy spectra of the counts. Because of the limitations in MCNP5 previously mentioned, only the experimental data and the MCNP-PoliMi run can actually generate an image. These are both shown below respectively in Figure 12. The black dots represent the actual location of the source. For both the experiment and MCNP-PoliMi, the correct location of the source is encompassed by the maximum likelihood region indicated in the images, although not as well as in the previous scenario.
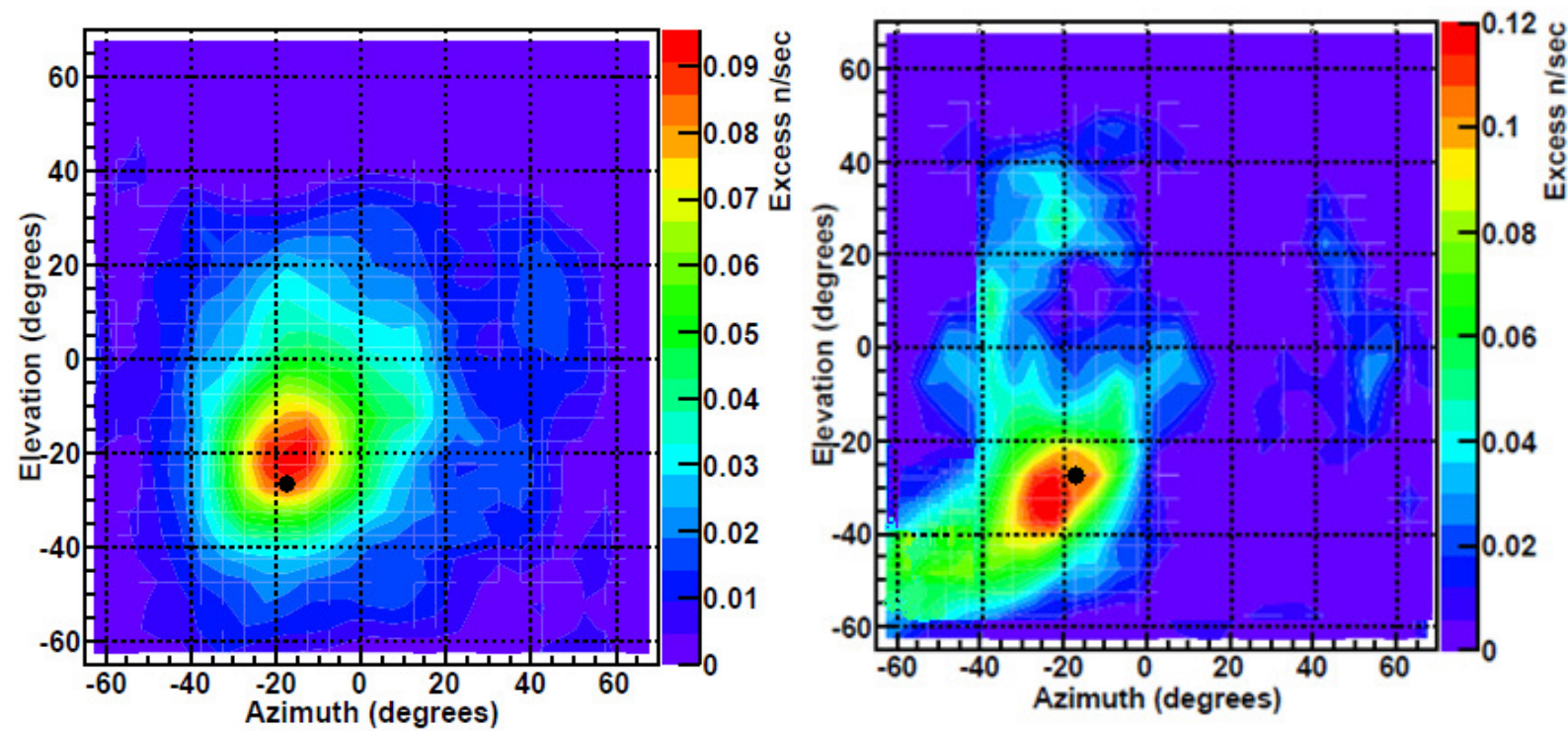

Figure 12. Experimental and MCNP-PoliMi iages for the second (shielded) Scatter Camera scenario.

The energy spectra of the counts that generated the images above in Figure 12 are also important to compare. For the MCNP5 and RADSAT simulations, the MCNP-PoliMi intrinsic efficiency is assumed to generate the spectra. This is what the spectra would look for those two codes if the same modification in the MCNP-PoliMi scattering were made in MCNP5 and RADSAT. A plot of these comparisons are shown below in Figure 13. As can be seen, they once again yield consistent results. 


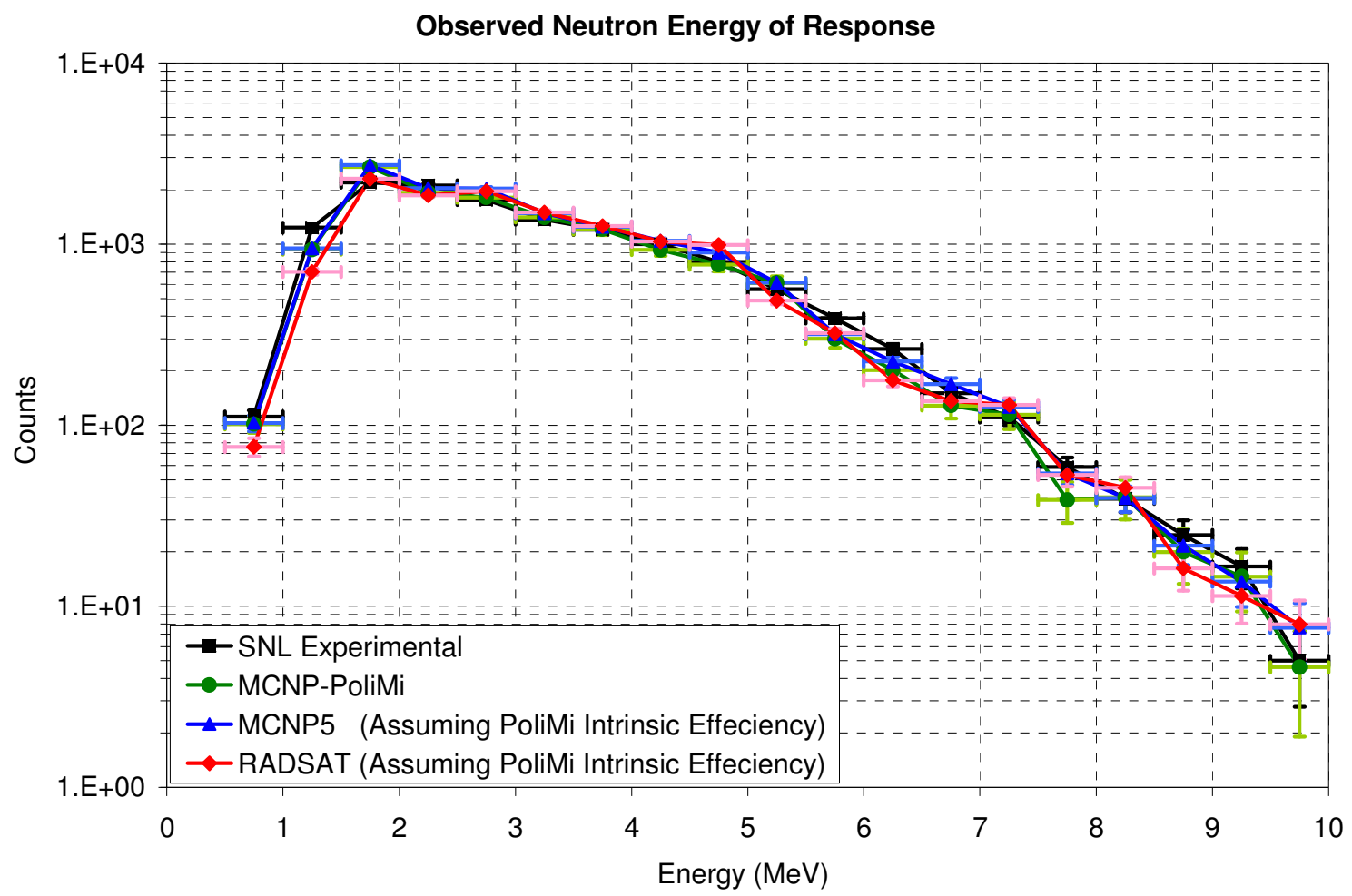

Figure 13. Comparison of detector responses for the second (shielded) Scatter Camera scenario.

Along with solution accuracy (both image and spectra), the other performance metric is computational run time. The results of both the computational accuracy and run times are compared below in Table 2 . The run times for this scenario were much longer than the previous scenario because of the transport through the shield/moderator. The MCNP-PoliMi results match the experimental data for both the image and the spectra. This shows that MCNP-PoliMi can faithfully simulate this scenario. MCNP5 and RADSAT results also match the experimental data (as well as MCNP-PoliMi) for the bulk transport and individual detector response. Assuming they would have the same intrinsic efficiency as MCNP-PoliMi, their spectra of the coincidence counts would match as well.

As for the run time, both MCNP5 and MCNP-PoliMi took almost two weeks to simulate the almost three and a half hour experimental run, while the RADSAT simulation took only about 2 days to simulate the same amount of real time. Therefore, RADSAT was more than seven times faster than MCNP5 for this scenario. This shows that there is possibly a computational advantage to using RADSAT for more complicated and realistic cases with scattering and shielding. It could be possible to reduce both the MCNP5 run times using variance reduction and the RADSAT run times using Attila's up-scatter acceleration capabilities as well as optimizing the deterministic parameters.

Table 2. Comparison of Results for the second (shielded) Scatter Camera scenario

\begin{tabular}{|c|c|c|c|}
\hline & $\begin{array}{c}\text { Image Location Solution } \\
\text { Accuracy (degrees) }\end{array}$ & $\begin{array}{c}\text { Spectral Solution } \\
\text { Accuracy }(\%)\end{array}$ & $\begin{array}{c}\text { Run Times for } \\
\text { Shielded Source (min) }\end{array}$ \\
\hline Experiment & $\sim 45^{\circ} \pm \sim 15^{\circ}$ & - & 201.12 \\
\hline MCNP-PoliMi & $\sim 7.0^{\circ} \pm \sim 15^{\circ}$ & $10.2 \%$ & $19,522.26$ \\
\hline MCNP5 & - & $12.2 \%$ & $19,509.05$ \\
\hline RADSAT & - & $11.9 \%$ & $2,699.96$ \\
\hline
\end{tabular}





\subsection{Modeling of the Spent Fuel Cask Gamma-Ray Scanner from INL}

The Spent Fuel Cask Gamma-Ray Scanner is a highly collimated detector that measures the gamma-ray response above each fuel assembly location in the cask. A visualization of the scanner is shown below in Figure 14 and the pattern over which it moves to scan all locations is shown below in Figure 15. Because spent fuel casks are made to shield the radiation from the spent fuel, this is a computationally expensive problem to solve by modeling.

To get around much of this difficulty, the Monte Carlo N-Particle eXtended (MCNPX) [12] model made by INL to evaluate the effectiveness of the detection system has multiple variance reduction techniques in it. First, due to self shielding of the assemblies, only the top $75 \mathrm{~cm}$ of the fuel is modeled. Next, there is source biasing in the upward direction toward the scanner. Finally, there are weight windows in sections of the cask lid to increase the gamma importance as the location becomes closer to the detector. All MCNPX simulations described below employ these variance reduction techniques, so the comparison of run times between MCNPX and RADSAT are both for optimized cases, and therefore, fair comparisons. To compare the run times, all actual computer run times were normalized to a single Intel Xeon E5506 $\mathrm{CPU}$ at $2.13 \mathrm{GHz}$ on a machine with a Microsoft Windows operating system.

One advantage of RADSAT for this scenario is that the flux can be taken above all assembly locations in a single run. The detector response could then be taken from each location, so the deterministic transport would only have to be run once and the detector response module of RADSAT, which runs on the order of minutes or tens of minutes, could be run for each location. Something similar could be done in MCNPX where the detector is modeled above each of the locations. However this would increase the complexity (and therefore, runtime) of the MCNPX model. Besides run time, total time to solution is important. For this problem it is time and effort intensive to set up the MCNPX model with correct variance reduction techniques. Variance reduction techniques require testing and iteration to optimize their effectiveness, whereas that is not required for the RADSAT model. Therefore, the time to set up the model in RADSAT should be less than that to set up the model in MCNPX.

The specific scenario provided by INL is for Turkey Point Nuclear Reactor spent fuel in a Westinghouse MC-10 spent fuel cask. A diagram of the cask and assembly locations is shown below in Figure 16. The two assembly positions that were modeled for comparison were the full $\mathrm{C} 2$ and empty A4 slots. These positions are indicated by being circled on in Figure 16. 


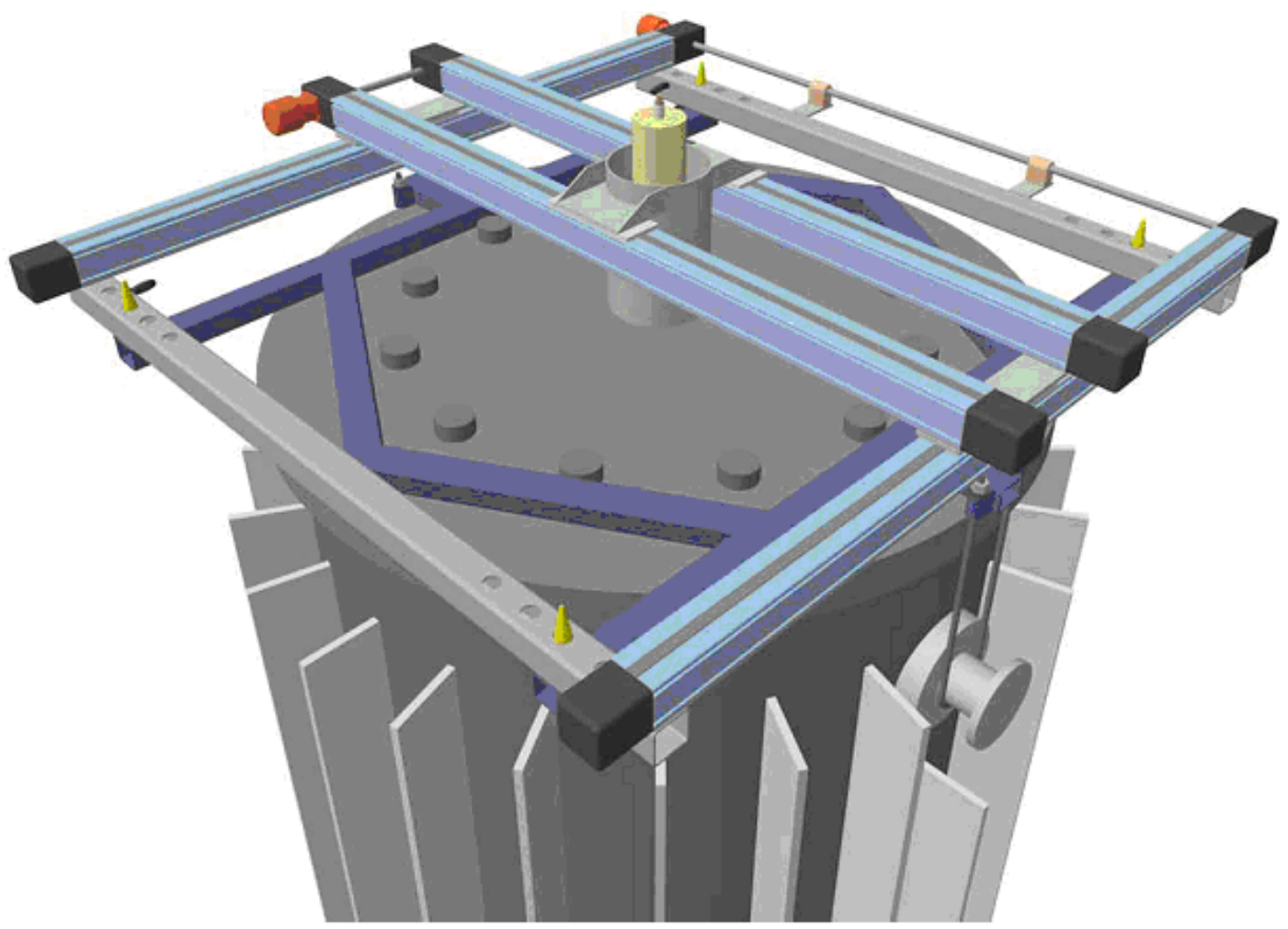

Figure 14. Visualization of the Cask Scanner on a Westinghouse MC-10 Spent Fuel Cask [13].

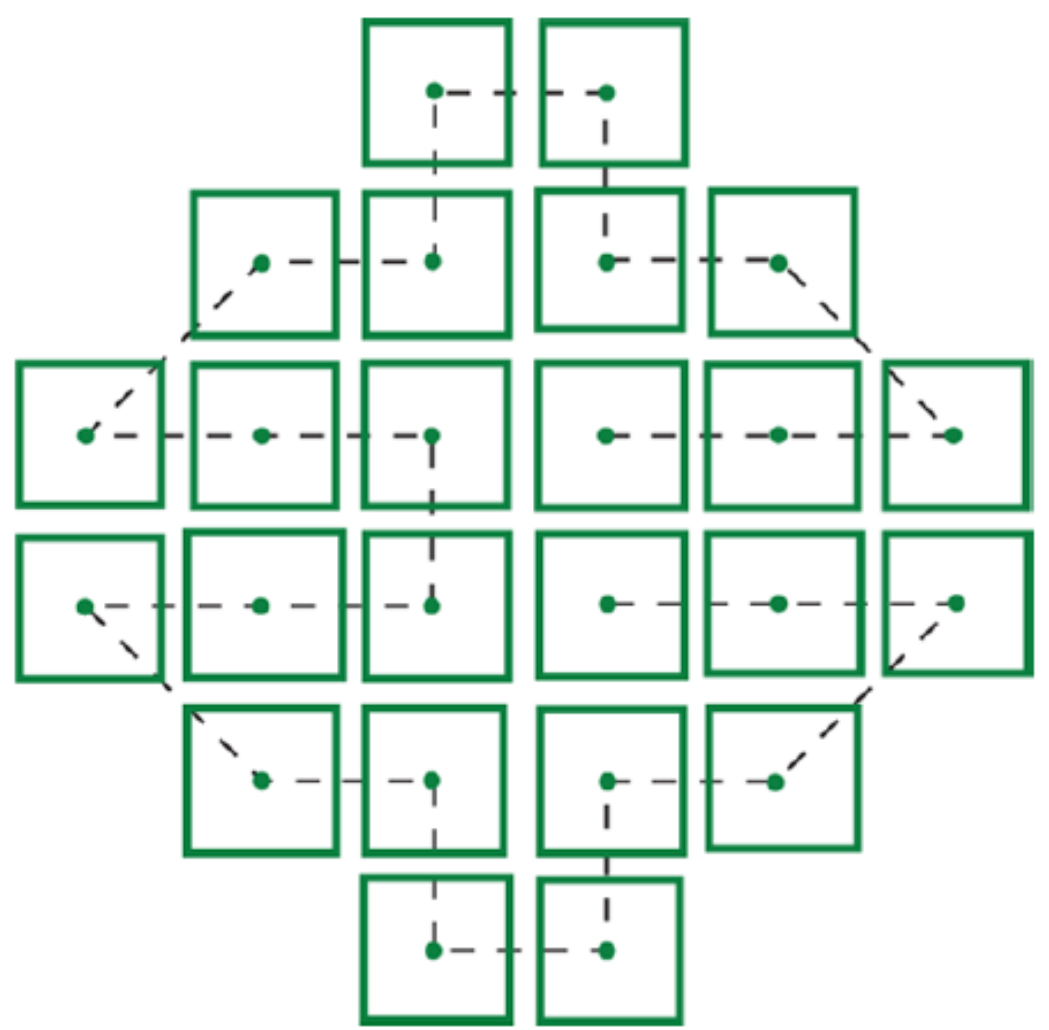

Figure 15. Assembly Scanning Pattern of a Westinghouse MC-10 Spent Fuel Cask [13]. 


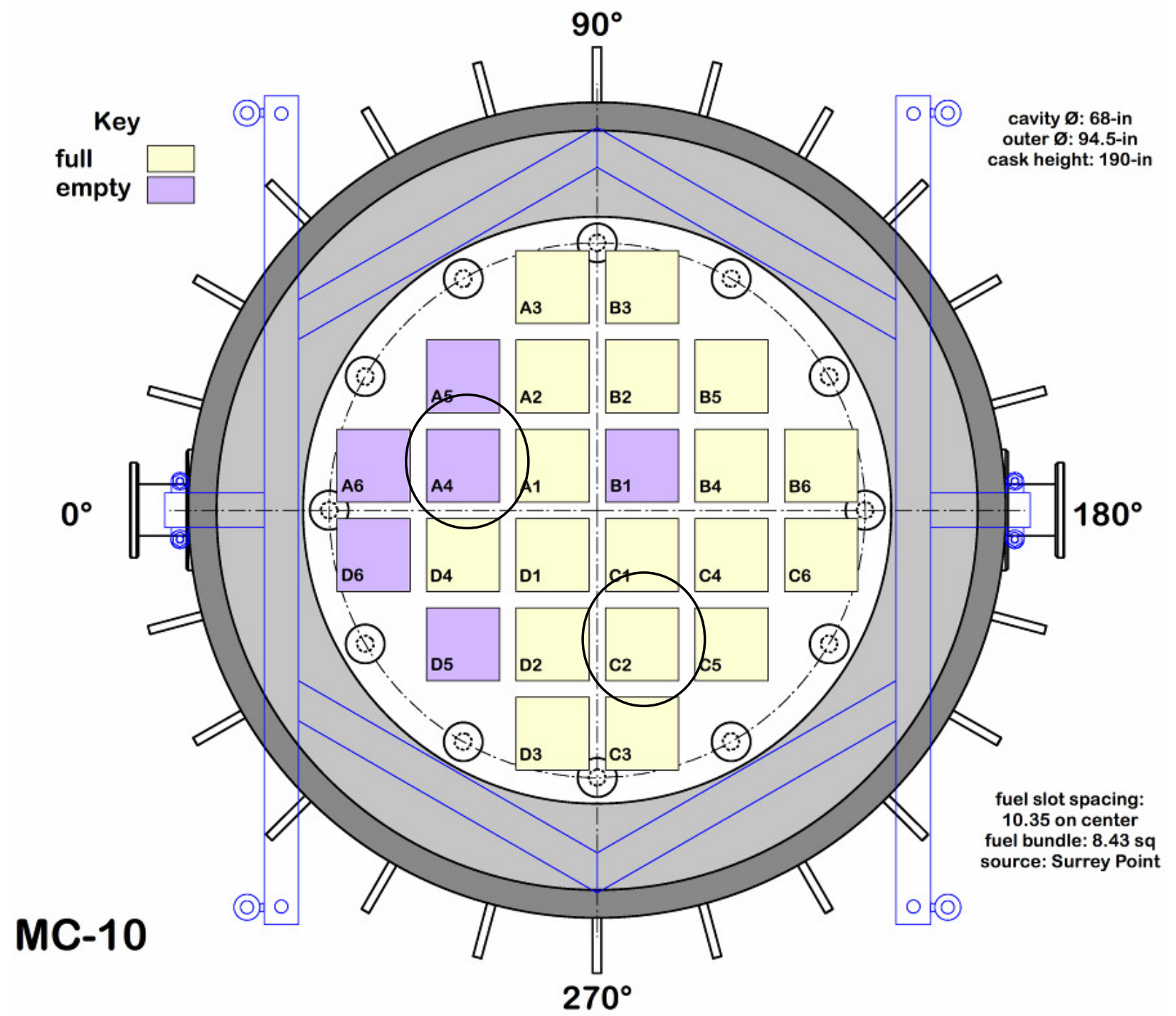

Figure 16. Configuration and assembly loading of the Turkey Point spent fuel cask [13]

To generate the gamma source term in the spent fuel the Origen-ARP Turkey Point PWR Sample Problem D1.4.4 was used [14]. The only modifications to the run were changing the burnup to 29 MWd/MTU and the cooling time to 29 years to match the particular cask that was measured. This source term was then used in both MCNPX and RADSAT full positions. Visualizations of the cask RADSAT model and the detector MCNP model are shown below in Figures 17 and 18 respectively. The MCNP model of the detector was used for both the RADSAT and MCNPX simulations. For the RADSAT simulation of the spent fuel cask scanner scenario, the mesh was meshed to a tightness of $0.1 \mathrm{~m}$ every where in the problem except for the lid, which was meshed to $0.05 \mathrm{~m}$. The cross section library used was 101 groups and generated by the CEPXS module of RADSAT. The maximum outer and inner iterations were both 100, and the convergence criterion was 1E-4. The quadrature used was Triangle Chebychev Lobatto, with an $\mathrm{S}_{\mathrm{N}}$ of order 8 and a $\mathrm{P}_{\mathrm{N}}$ of order 2, and Galerkin Scattering turned on. A point source flux edit was taken by space and energy at points centered above each assembly. 

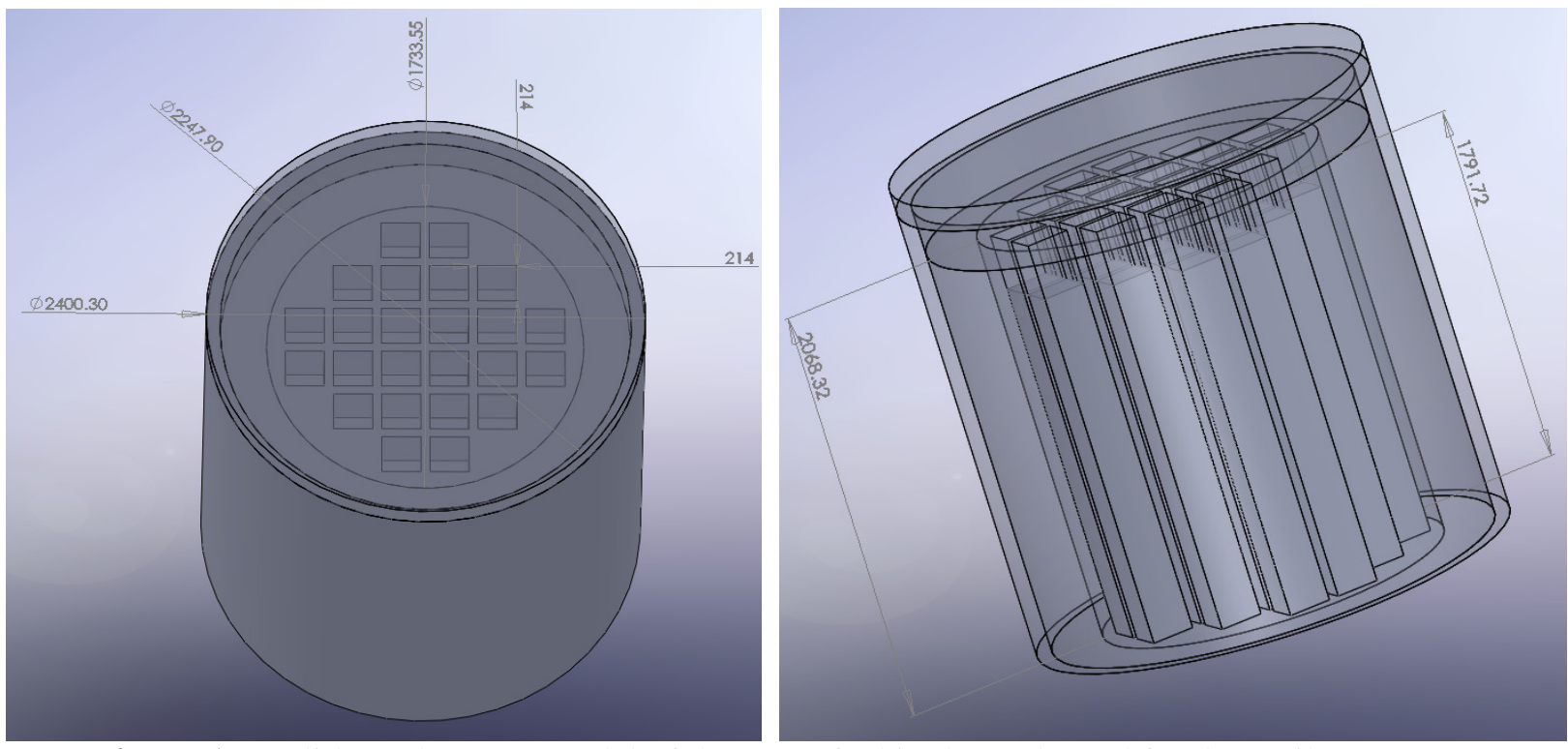

Figure 17. Solid Works CAD model of the spent fuel in the cask used for the Attila geometry

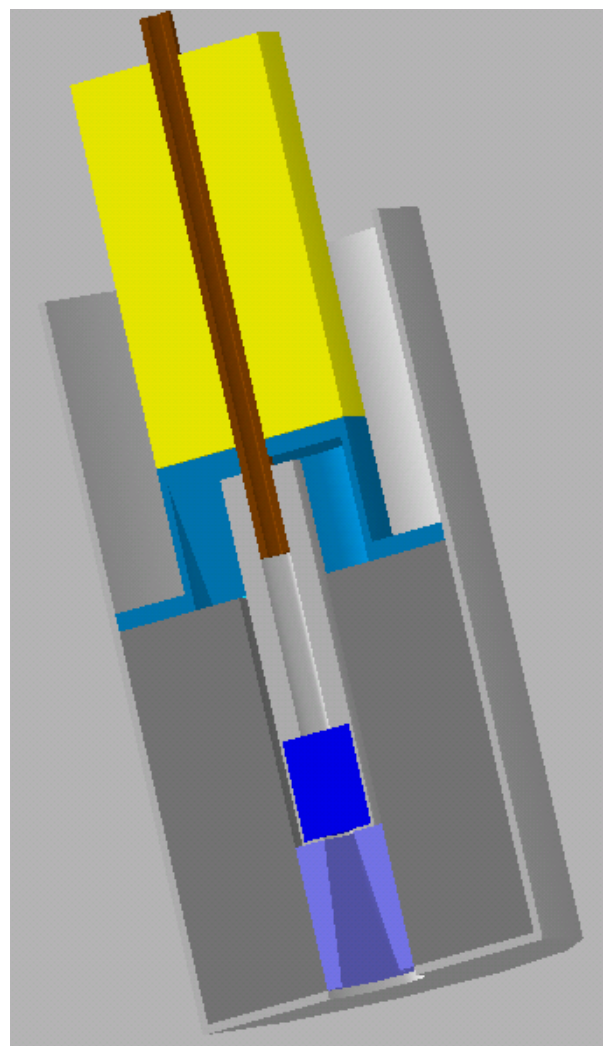

Figure 18. Visualization of the MCNPX Model of the collimated gamma detector. 


\subsection{Modeling of the Full C2 Assembly Position}

The spectral results of the experimental data, MCNPX and RADSAT for the full C2 assembly position are shown for comparison below in Figure 19. For analysis of the spent fuel, INL looks at the spectra between $700 \mathrm{keV}$ and $1100 \mathrm{keV}$ as well as certain peaks from different isotopes. The peaks of interest are shown above in Figure 19 and include $662 \mathrm{keV}$ from ${ }^{137} \mathrm{Cs}, 1173 \mathrm{keV}$ from ${ }^{60} \mathrm{Co}, 1274 \mathrm{keV}$ from ${ }^{254} \mathrm{Eu}$, and $1332 \mathrm{keV}$ from ${ }^{60} \mathrm{Co}$.

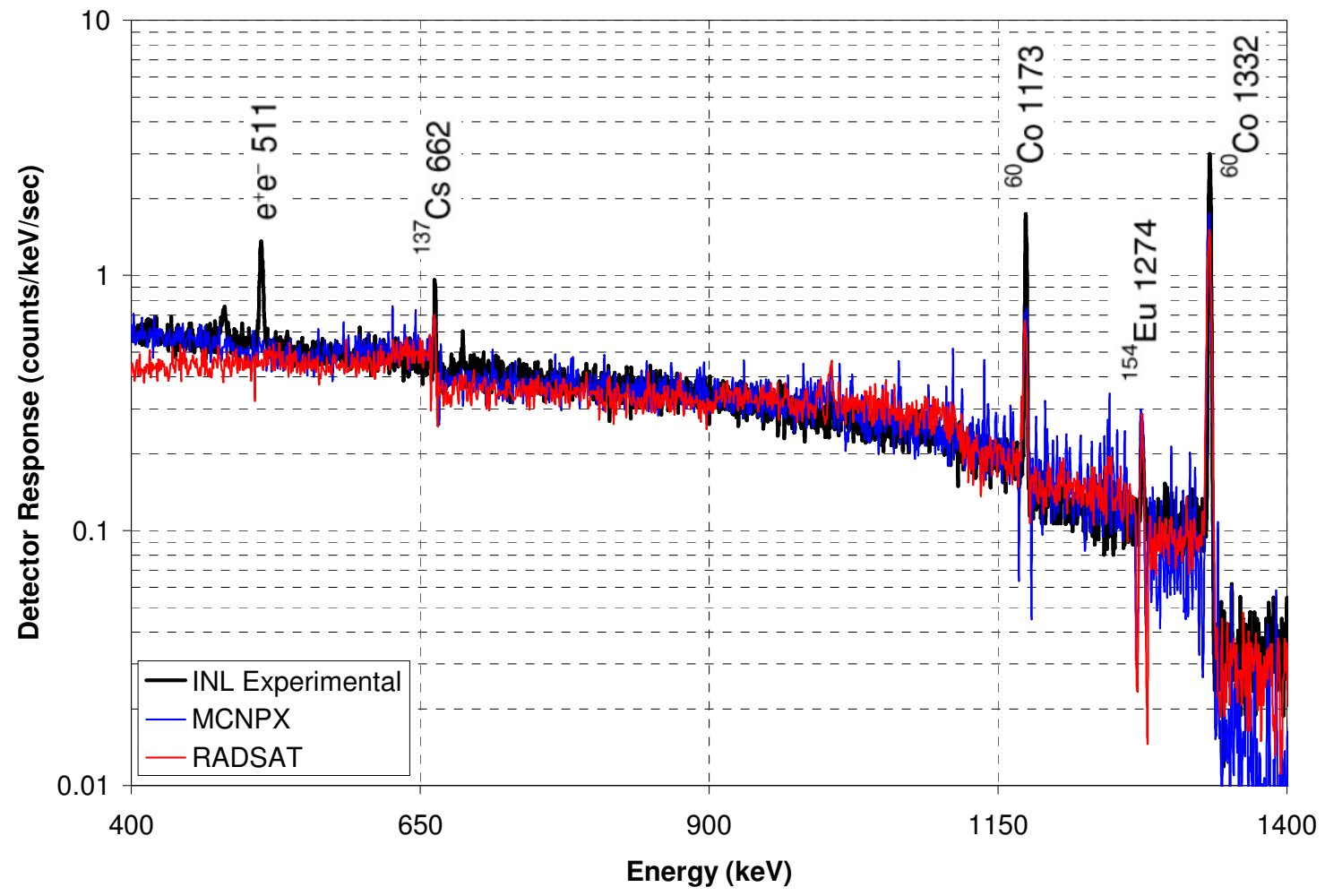

Figure 19. Comparison of Cask Scanner Detector Response in the full C2 slot.

A comparison of the two simulations methods is compared to the experimental data in Table 3 below. The comparison metric is the integrated area under the energy region for the spectra and the integrated area under the peaks for the discrete isotope lines. As can be seen MCNPX and RADSAT yield consistent results with each other and with the experimental data, less than $15 \%$ deviation from experimental in all cases. In terms of run time, it took MCNPX over two days to simulate the 1,000 minutes of detector live time and RADSAT took just over one day to simulate the same detector live time. This means that RADSAT took less than $60 \%$ of the time of MCNPX to yield comparable answers. Both codes have been optimized for the best run time, including the MCNPX variance reduction mentioned previously.

Table 3. Comparison of Results for the Cask Scanner in the full C2 slot

\begin{tabular}{|c|c|c|c|c|c|c|}
\hline & $\begin{array}{c}700-1,100 \\
\mathrm{keV}(\%)\end{array}$ & $\begin{array}{c}662 \mathrm{keV} \\
\text { Peak (\%) }\end{array}$ & $\begin{array}{c}1173 \mathrm{keV} \\
\text { Peak (\%) }\end{array}$ & $\begin{array}{c}1274 \mathrm{keV} \\
\text { Peak (\%) }\end{array}$ & $\begin{array}{c}1332 \mathrm{keV} \\
\text { Peak (\%) }\end{array}$ & $\begin{array}{c}\text { Run Time } \\
(\mathrm{min})\end{array}$ \\
\hline INL - Experimental & - & - & - & - & - & 1,000 \\
\hline MCNPX & $14.3 \%$ & $14.7 \%$ & $-6.77 \%$ & $5.72 \%$ & $-8.20 \%$ & 2,916 \\
\hline RADSAT & $11.9 \%$ & $14.1 \%$ & $-10.6 \%$ & $-14.2 \%$ & $-10.5 \%$ & 1,687 \\
\hline
\end{tabular}




\subsection{Modeling of the Empty A4 Assembly Position}

The spectral results of the experimental data, MCNPX and RADSAT for the empty A4 assembly position are shown for comparison below in Figure 19. For analysis of the spent fuel, INL looks at the spectra between $700 \mathrm{keV}$ and $1100 \mathrm{keV}$ as well as certain peaks from different isotopes. The peaks of interest are shown above in Figure 19 and include $662 \mathrm{keV}$ from ${ }^{137} \mathrm{Cs}, 1173 \mathrm{keV}$ from ${ }^{60} \mathrm{Co}, 1274 \mathrm{keV}$ from ${ }^{254} \mathrm{Eu}$, and $1332 \mathrm{keV}$ from ${ }^{60} \mathrm{Co}$.

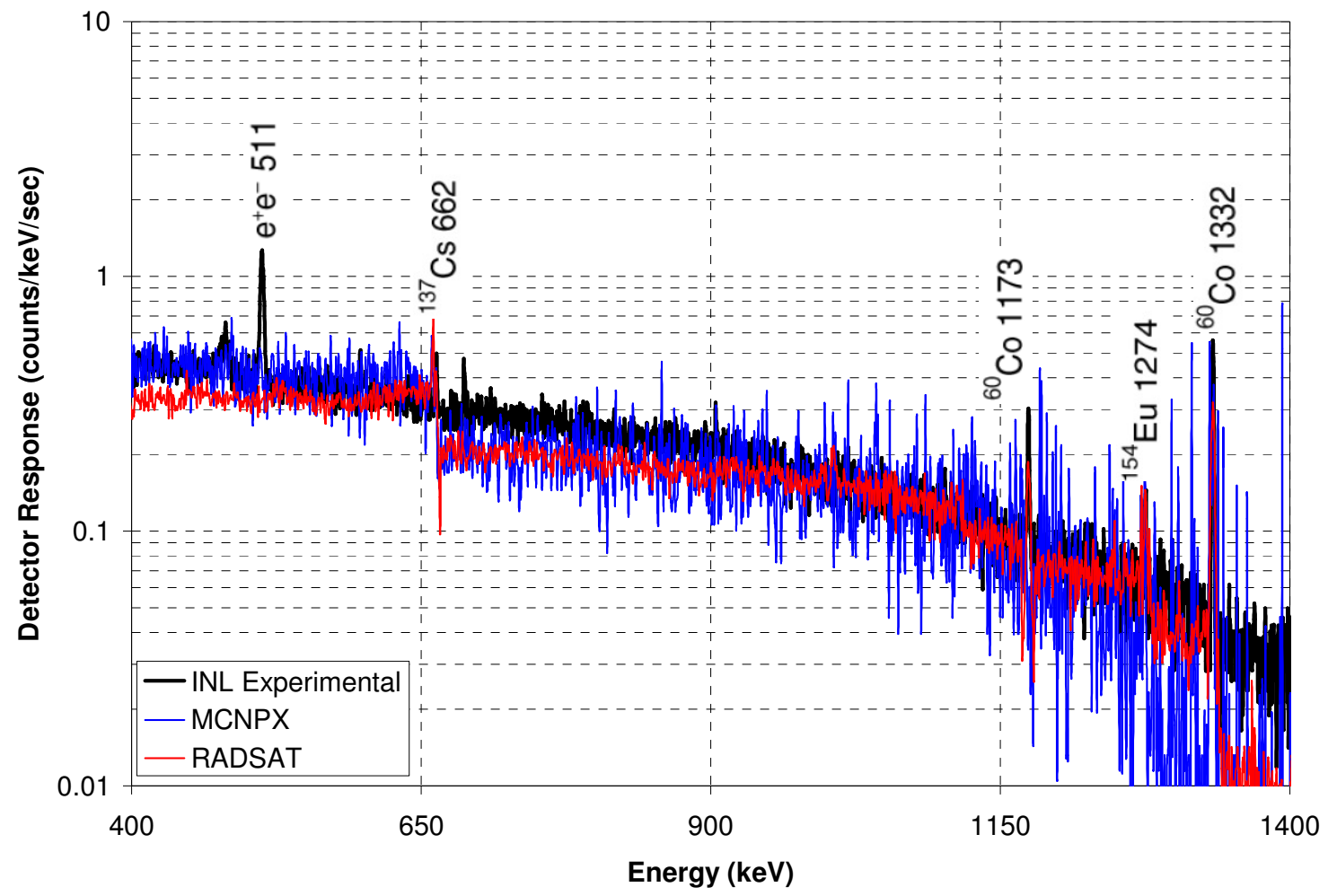

Figure 20. Comparison of Cask Scanner Detector Response in the empty A4 slot.

A comparison of the two simulations methods is compared to the experimental data in Table 4 below. The comparison metric is the integrated area under the energy region for the spectra and the integrated area under the peaks for the discrete isotope lines. As can be seen MCNPX and RADSAT yield consistent results with each other and with the experimental data, less than $15 \%$ deviation from experimental in all cases. In terms of run time, it took MCNPX over two days to simulate the 1,000 minutes of detector live time and RADSAT took just over one day to simulate the same detector live time. This means that RADSAT took less than $60 \%$ of the time of MCNPX to yield comparable answers. Both codes have been optimized for the best run time, including the MCNPX variance reduction mentioned previously.

Table 4. Comparison of Results for the Cask Scanner in the empty A4 slot

\begin{tabular}{|c|c|c|c|c|c|c|}
\hline & $\begin{array}{c}700-1,100 \\
\mathrm{keV}(\%)\end{array}$ & $\begin{array}{c}662 \mathrm{keV} \\
\text { Peak (\%) }\end{array}$ & $\begin{array}{c}1173 \mathrm{keV} \\
\text { Peak (\%) }\end{array}$ & $\begin{array}{c}1274 \mathrm{keV} \\
\text { Peak (\%) }\end{array}$ & $\begin{array}{c}1332 \mathrm{keV} \\
\text { Peak (\%) }\end{array}$ & $\begin{array}{c}\text { Run Time } \\
(\min )\end{array}$ \\
\hline INL - Experimental & - & - & - & - & - & 1,000 \\
\hline MCNPX & $2.09 \%$ & $12.3 \%$ & $-4.23 \%$ & $-14.5 \%$ & $1.44 \%$ & $2.09 \%$ \\
\hline RADSAT & $-0.811 \%$ & $10.9 \%$ & $13.3 \%$ & $10.1 \%$ & $-1.59 \%$ & $-0.811 \%$ \\
\hline
\end{tabular}




\subsection{Comparison of the Modeling of the Full C2 and Empty A4 Assembly Positions}

Comparing the two assembly position cases (the full C2 slot and the empty A4 slot) produces Figure 21 below. It is apparent that both MCNPX and RADSAT faithfully represent the difference in magnitude in the spectra between the full and empty locations in the cask.

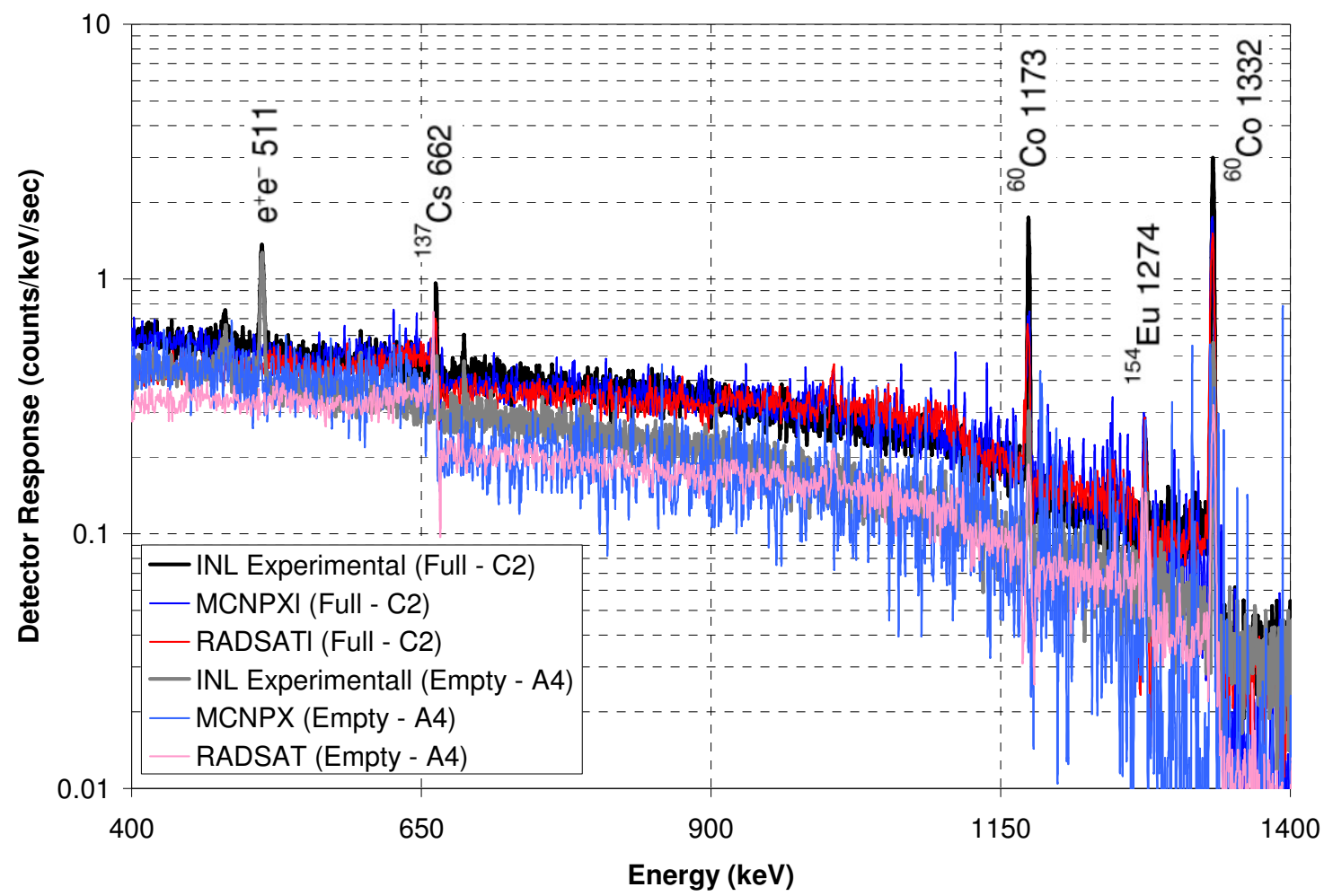

Figure 21. Comparison of Cask Scanner Detector Response in the full C2 and empty A4 slots

It is important to note that there are certain features in the simulated data that are not apparent in the experimental data and vice versa. The $511 \mathrm{keV}$ peak does not show up in the simulated data because the positron annihilation after pair production is not modeled in the Monte Carlo simulations. Therefore, this peak does not show up in either MCNPX or RADSAT. Also, it is quite common for simulated gammaray detector responses show fewer counts than experimental data in the energies just higher than a peak. Again this feature is apparent for both MCNPX and RADSAT. Lastly, the peak heights do not completely match up in the simulated data because of the Gaussian energy broadening terms not being quite the same as the measured data. The metric compared is the integrated counts under each of the peaks or the region of interest.

The only computational feature not shared between MCNPX and RADSAT results is that RADSAT does begin to deviate somewhat in the lower energies due to scattering parameters and convergence. These issues could be resolved to match the spectra at lower energies with longer run times. That was not done for these cases because it is below the region of interest for the problem. 


\subsection{Conclusions}

The detector response module of RADSAT uses MCNP5, which does not produce all of the information required for the SNL scatter camera data processing code. SNL models the scatter camera with MCNPPoliMi, which utilizes more accurate neutron elastic scattering physics and secondary gamma-ray production essential for modeling time-dependent events in multiple detectors. Therefore, RADSAT currently will not work for generating images for the scatter camera system. However, another metric used to compare simulated results from RADSAT and MCNP-PoliMi is the individual detector responses. It was demonstrated that the count rates and spectra in the detectors are consistent for RADSAT, MCNP5, MCNP-PoliMi, and the experimental data. This indicates that RADSAT could be an appropriate tool for modeling scatter cameras if MCNP-PoliMi were to be used as the RADSAT Monte Carlo detector response module. Incorporating MCNP-PoliMi into RADSAT in addition to MCNP5 would require a minimal amount of code development, testing, and quality assurance.

For simple and low to no scattering problems, there may not be a computational speed advantage for RADSAT over MCNP5, but for more complicated, larger, or neutron scattering problems (which are probably more realistic), RADSAT may have computational run times shorter than MCNP5. While variance reduction can help speed up the MCNP5 simulations, more large and complex scenarios may see a larger advantage for RADSAT in terms of computational speed.

For the simulation of the spent fuel cask gamma-ray scanner, the solution accuracies for the RADSAT simulations were reasonable (less than $15 \%$ different from experimental results) and comparable to the current standard (MCNPX) for all of the compared values for both the full and empty assembly positions. RADSAT also ran 60\% faster than MCNPX, with both codes optimized for speed. Also, the time to set up the RADSAT run is probably much less than the time to set up and optimize an MCNPX input deck with appropriate variance reduction, making the total time to solution even faster for RADSAT than just the computational run time advantage. 


\subsection{References}

[1] McGhee J, Wareing TA, Barnett DA. “Attila User's Manual,” Gig Harbor, WA, Transpire, Inc., 2007

[2] X-5 Monte Carlo Team, "MCNP - A General Purpose Monte Carlo N-Particle Transport Code, Version 5," LA-UR-03-1987, Los Alamos National Laboratory, April 2003.

[3] L. E. Smith, J.E. Ellis, C.J. Gesh, R.J. McConn, G.H. Meriwether, E. Miller, R.T. Pagh, A.B. Valsan, T. Wareing, "Deterministic Transport Methods for the Simulation of Gamma-Ray Spectroscopy Scenarios," IEEE Transactions on Nuclear Science, Vol. 55(5), pp. 2598-2606, October 2008.

[4] M. W. Shaver, L. E. Smith, R. T. Pagh, E. A. Miller, R. S. Wittman, "The Coupling of a Deterministic Transport Field Solution to a Monte Carlo Boundary Condition for the Simulation of Large Gamma-Ray Spectrometers," accepted for publication in Nuclear Technology, June 2008.

[5] K. Burns, L.E. Smith, C.J. Gesh, M.W. Shaver, "A Coupled Deterministic-Monte Carlo Approach for the Simulation of Prompt Gamma Neutron Activation Analysis," 2009 International Conference on Mathematics, Computational Methods and Reactor Physics, Saratoga Springs, New York, May 2009.

[6] A.M. Casella, C.J. Gesh, L.E Smith, "Use of Detector Response Functions and Deterministic Flux Calculations in Count Rate Predictions," submitted to American Nuclear Society Transactions, July 2009.

[7] S.A. Pozzi, E. Padovani, and M. Marseguerra, "MCNP-PoliMi: a Monte-Carlo code for correlation measurements," Nuclear Inst. and Methods in Physics Research, A, vol. 513, no. 3, pp. 550-558, 2003.

[8] S. Pozzi, "Recent Developments in the MCNP-PoliMi Postprocessing Code," United States. Dept. of Energy, 2004.

[9] C. H. Greenberg, J. Brennan, N. Mascarenhas et al., "Exploring neutron scatter camera performance using MCNP-PoliMi." pp. 1274-1276.

[10] N. Mascarenhas, J. Brennan, C. H. Greenberg et al., "Field-portable fast-neutron imager for SNM detection." pp. 944-946.

[11] N. Mascarenhas, J. Brennan, K. Krenz et al., "Results With the Neutron Scatter Camera," Nuclear Science, IEEE Transactions on, vol. 56, no. 3, pp. 1269-1273, 2009.

[12] Waters, L.S., Editor, “MCNPX User's Manual, Version 2.3.0,” LA-UR-02-2607, Los Alamos National Laboratory, April 2002.

[13] A.J. Caffrey, "Recent Test Results for the INL Spent-Fuel Cask Gamma-Ray Scanner," Present at the IAEA US SP Annual Meeting Presented on May 19, 2009.

[14] S. M. Bowman and L. C. Leal, "Origen-ARP: Automatic Rapid Process for Spent Fuel Depletion, Decay, and Source Term Analysis," NUREG/CR-0200, Revision 6, Volume 1, Section D1,

ORNL/NUREG/CSD-2/V1/R6, 2000. 
PNNL-19795

\section{Distribution}

No. of

Copies

1 David Beach

Department of Energy

NNSA NA-22

1000 Independence Ave.

Washington, DC 20585
No. of

\section{Copies}

2 Local Distribution

Pacific Northwest National Laboratory

M.W. Shaver (1)

K8-41

Information Release (1)

(PDF) 


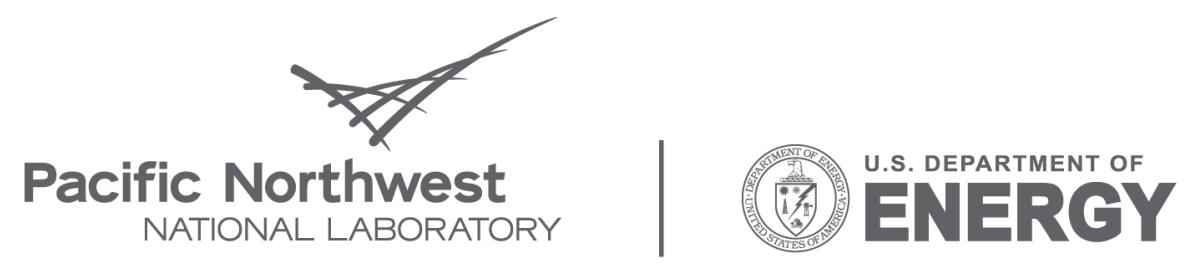

Proudly Operated by Battelle Since 1965

902 Battelle Boulevard

P.O. Box 999

Richland, WA 99352

1-888-375-PNNL (7665)

www.pnl.gov 